\title{
Posted Prices, Search and Bargaining
}

\author{
Derek Stacey*
}

May 6, 2019

\begin{abstract}
A model of a decentralized market is developed that features search frictions, advertised prices and bargaining. Sellers can post ask prices to attract buyers through a process of directed search, but ex post there is the possibility of negotiation. Similarly, buyers can advertise negotiable bid prices to attract sellers. Even when transaction prices often differ from quoted prices, bid and ask prices play a crucial role in directing search and reducing trading frictions. The theory endogenizes the direction of search and provides insight about the prevalence of posted prices in the absence of full commitment by market participants to transact at the advertised price.
\end{abstract}

Journal of Economic Literature Classification: D40, G12, L10

Keywords: Bid and Ask Prices, Search Frictions, Price Commitment.

\footnotetext{
*Ryerson University, Department of Economics, 350 Victoria Street, Toronto, Ontario, M5B 2K3, Canada, dstacey@economics.ryerson.ca. Financial support from the Social Sciences and Humanities Research Council of Canada (Insight Development Grant No. 430-2016-0292) is gratefully acknowledged. For helpful comments I thank James Albrecht, Sonja Chen, Mohammad Davoodalhosseini, Antonia Díaz, Ben Lester, Sephorah Mangin, Shouyong Shi, Randy Wright, and participants of the Vienna Macro Conference (2014), the Housing-Urban-Labor-Macro (HULM) Conference (Spring 2015), the Society for Economic Dynamics (SED) Annual Meeting in Warsaw (2015), the North American Winter Meetings of the Econometric Society in San Francisco (2016), the Canadian Economics Association Conference in Ottawa (2016), the Canadian Macroeconomics Study Group (CMSG) Annual Meeting in Kingston (2016), the RED Fragmented Markets Conference in Philadelphia (2018), and seminars at McMaster, Wilfrid Laurier and Waterloo.
} 


\section{Introduction}

When ex post bargaining leads to transaction prices that diverge from original advertised prices, it seems sensible to question the very relevance of price posting. In this paper I develop a dynamic model of a decentralized market to show that even negotiable prices can be advertised strategically as a means of directing search and reducing trading frictions. I allow either side of the market to post prices so that the direction of search is determined endogenously and depends on the details of the bargaining procedure. I consider the implications of bilateral price negotiations for (i) posted and final prices, (ii) the set of traders posting prices in equilibrium, and (iii) market efficiency. Finally, I show that the features and price-related predictions of the model align well with aspects of a decentralized secondary market for a particular security: namely, transferable taxicab license plates in Toronto.

A considerable amount of economic activity transpires in frictional markets that feature transaction prices that do not always equal advertised prices. Examples of financial assets traded in such markets include fixed income securities and mortgage loans. Other non-financial examples include durable goods such as houses, used vehicles and appliances; uncommon or unusual items such as rare wine, fine art or antiques; and services such as those provided by skilled tradespeople and child caregivers. Prices are advertised by supply-side participants in some markets, while other markets feature prices posted by buyers. In the context of the financial markets referenced above, banks post prices/rates that appeal to savers (in the case of fixed income securities) and borrowers (in the case of mortgage loans). In non-financial contexts, platforms for classified advertisements often feature listings/prices from one or both sides of the market (i.e., "I am offering" versus "I am seeking" ads). To understand these seemingly puzzling observations, I develop a search model with posted prices and bargaining. The theory rationalizes the prevalence of price posting even 
when transaction prices differ from posted prices, and provides an explanation for why trading opportunities are proposed by one side of the market or the other. The model can even account for price posting on both sides of the market.

These insights and implications are derived from a dynamic model of a decentralized market characterized by a trading process with three key features: prematch communication, search frictions, and a strategic method of price determination. Traders on either side of the market have the opportunity to post a public advertisement containing an ask price (a seller's quoted price or list price) or a bid price (a buyer's offer-to-purchase price). Next, buyers and sellers meet stochastically according to a bilateral matching technology. Search is directed in the sense that searching traders first observe all public advertisements and then target a particular price in their search. An assumption of the model is that matches occur between traders that passively post prices and those that instead decide to actively search. Transaction prices are then determined in a bargaining game between a matched buyer and seller, where the posted price is interpreted as the initial offer in an alternating offer bargaining game. The initial advertisement conveys limited commitment to a price because the counterparty that has not engaged in pre-match price publication maintains the ability to trigger ex post negotiation.

In a setting where there is ex ante uncertainty about a trader's relative bargaining strength, negotiated premiums/discounts relative to advertised bid/ask prices arise in equilibrium whenever bargaining favors the trading partner that is not constrained by a commitment to a posted price. It follows that the possibility of unfavorable outcomes in the bargaining procedure generates incentives for potential trading partners to direct their search towards a certain bid or ask price. If the seller's expected bargaining strength is sufficiently high, for example, an ask price effectively limits the seller's share of the surplus and can therefore be chosen strategically as a means of 
attracting a buyer. The strategic role of an ask price is therefore somewhat related to that in Chen and Rosenthal (1996a,b) and Arnold (1999), where a seller sets an asking price to effect a price ceiling which encourages a buyer to incur the cost of inspecting the item for sale. ${ }^{1}$ In an environment where sellers compete for buyers, Lester, Visschers, and Wolthoff (2017) show that an asking price mechanism provides both an appropriate means of attracting buyers and sufficient motivation to incur the inspection cost. Even in the absence of idiosyncratic values (observable or otherwise) and costly inspection, I show that an appropriately chosen ask price should appeal to buyers if it insures them against detrimental outcomes in price negotiations. Moreover, the opportunity to post a bid price permits a buyer to implement an analogous technique for seducing sellers. The details of the ex post bargaining procedure determine which traders post prices and which traders actively search in equilibrium. In other words, the direction of search is determined endogenously and depends on the expected division of bargaining power. ${ }^{2}$

Constrained efficiency in this environment can be described by an optimal ratio of buyers to sellers given search frictions and the cost of market participation. Decentralizing the constrained efficient allocation requires a surplus-splitting rule that assigns to each trader their marginal contribution to the match (in expectation). ${ }^{3}$ Absent agreement to this division of surplus, ex post bargaining generically assigns too much

\footnotetext{
${ }^{1}$ An asking price is relevant in these settings because buyers have idiosyncratic valuations (i.e., willingness to pay) that become common knowledge after the inspection. Consequently, buyers might capture too little of the expected surplus to justify incurring the inspection cost unless sellers commit ahead of time to a price ceiling.

${ }^{2}$ Halko, Kultti, and Virrankoski (2008) and Kultti et al. (2009) also endogenize search direction, but do not model publicly advertised offers. Delacroix and Shi (2018) study the market efficiency implications of which side of the market organizes trade and provide an exposition based on the participation and site costs, the elasticity of market participation on each side, and the properties of the matching technology. They show that the constrained efficient allocation can be implemented in an environment with directed search, endogenous market organization, and full commitment to posted prices.

${ }^{3}$ This is a well-known condition for constrained efficiency in markets with search frictions (Mortensen, 1982b; Hosios, 1990).
} 
or too little of the surplus to buyers, which distorts their entry decisions and reduces the joint surplus. Models of directed search typically provide incentive for agents to post and commit to mechanisms that maximize the joint surplus. ${ }^{4}$ The mechanism I consider allows for ex post negotiations arising from limited commitment to posted offers ${ }^{5}$ but affords enough flexibility to deliver the constrained efficient level of surplus provided the appropriate side of the market engages in price posting (i.e., the side of the market that would otherwise capture too much surplus). The constrained efficient direction of search emerges endogenously in equilibrium. Bid prices are advertised in settings where, absent posted prices, ex post negotiations tend to favor the demand side of the market which creates incentives for too many market participants. The inverse is also true: ask prices are posted when bargaining favors the supply side of the market leading to less than the optimal ratio of buyers to sellers.

In the context of frictional financial markets, it is worth noting again that banks post prices/rates for financial products and services that appeal to both savers (e.g., fixed income securities) and borrowers (e.g., mortgage loans) even though customers regularly negotiate premiums/discounts. The model presented here offers a search and bargaining related explanation premised on banks having an advantage over consumers in price/rate negotiations: a plausible assumption if the frequency of negotiations is a source of bargaining prowess. A straightforward extension of the theory to an environment with ex post trader heterogeneity can account for the coexistence of bid and ask prices in equilibrium. An implication that follows is that ask prices exceed the average transaction price, whereas bid prices lie below the average sale price.

\footnotetext{
${ }^{4}$ For example, sellers can post and commit to prices in Burdett, Shi, and Wright (2001), whereas sellers post and commit to a selling mechanism (e.g., second-price auction with reserve price) in Albrecht, Gautier, and Vroman (2014).

${ }^{5}$ Limited commitment to posted prices have been studied in related but notably different settings. For example, Albrecht, Gautier, and Vroman (2015) develop a directed search model of a housing market with limited commitment to initial offers that are not contingent on realized demand, while Camera and Selcuk (2009) advance a strategic renegotiation process in a directed search model with posted prices and multilateral (i.e., one-to-many) meetings to study price dispersion.
} 
As an interesting illustration of these outcomes, I consider the secondary market for transferable standard taxicab licenses (STLs) in Toronto. These are license plates that can not only be used by an owner-driver to operate a taxicab vehicle in Toronto, but can also be leased, rented to shift drivers or transferred to a new owner by means of a transaction in the secondary market. The assets being exchanged in this market (i.e., the standard taxicab licenses) are homogeneous, but are nevertheless traded in a decentralized manner; buyers and sellers publish negotiable prices and search for each other by means of an online platform for classified advertisements. The advertised prices and transaction data support the theoretical implications insofar as advertised ask prices are typically higher than transaction prices, while advertised bid prices are lower. The qualitative characteristics of the price distributions lend support to the mechanism proposed in the theory based on strategically chosen bid and ask prices that direct search but are subject to bilateral negotiation.

The remainder of the paper is organized as follows. Section 2 describes the model environment. The equilibrium strategies for bargaining and price posting are characterized in Section 3. Section 3 also defines a steady state directed search equilibrium with posted prices. The positive implications of the model are illustrated in Section 4 by means of simulated examples and special cases. Section 5 extends the model to include variation in both the size and division of the match surplus by allowing for ex post heterogeneity in holding costs. Section 5 also presents evidence from the secondary market for STLs and argues that aspects of this market align well with the features and predictions of the theory. Section 6 concludes.

\subsection{Additional Related Literature}

The model is one of directed search and bargaining. In the literature on random search, the terms of trade are typically determined ex post by means of a bargaining 
protocol (Diamond, 1982; Mortensen, 1982a,b; Pissarides, 1984, 1985; Mortensen and Pissarides, 1994). In contrast, the terms of trade are publicly posted in a competitive search model akin to those studied by Montgomery (1991), Peters (1991), and Moen (1997), and market participants have the ability to commit not to renegotiate. In many markets, the actual transaction prices often differ from the advertised terms of trade because of ex post negotiation. The search model proposed in this paper can account for this and at the same time establishes a link between a posted price and the trader's matching probability. Pre-match price announcements direct search and efficiently reduce trading frictions despite traders' limited ability to use a bid or ask price as a firm commitment to transact at a particular price. ${ }^{6}$ As mentioned above, a novel and appealing part of the theory relative to the existing directed search literature is that the set of traders posting prices is not imposed exogenously.

Search and bargaining models currently represent a prominent theoretical framework for studying over-the-counter (OTC) financial markets in which traders/investors must identify a suitable counterparty and interact bilaterally in order to carry out a transaction. Models of unmediated decentralized asset markets with random search and bargaining include, among others, Duffie, Gârleanu, and Pedersen (2007); Hugonnier, Lester, and Weill (2014); and Afonso and Lagos (2015). The competitive search equilibrium approach with full commitment to posted prices is briefly introduced in the context of unmediated OTC markets by Rocheteau and Weill (2011), while Watanabe (2013) and Lester, Rocheteau, and Weill (2015) apply competitive search to asset markets where trades are intermediated by dealers. In contrast, I formalize a model of decentralized exchange that features both directed search and bargaining. For ap-

\footnotetext{
${ }^{6}$ Other papers in the directed search literature have studied the efficiency implications of removing or relaxing the assumption of commitment to a posted price (e.g., Menzio, 2007; Doyle and Wong, 2013; Kim and Kircher, 2015; Albrecht, Gautier, and Vroman, 2015; and Stacey, 2016). In the model presented in this paper, a trader can commit to honoring the posted price, but their counterparty in a match may not agree to it and instead elect to negotiate.
} 
plications to specific OTC financial markets, the environment is sufficiently tractable that it could be extended relatively easily along several dimensions to include, for example, trader heterogeneity, private information, and intermediation.

\section{The Environment}

Time is discrete and indexed by $t$. There is a large number of infinitely-lived agents. Some of them are initially endowed with one indivisible long-lived asset. Let $A$ denote the number of agents endowed with the asset, or equivalently, the total supply assets in the economy. For simplicity, assume that each agent can hold at most one unit of the asset. $^{7}$

Preferences. Agents are risk-neutral with common discount factor $\beta \in(0,1)$. The asset yields a dividend $d$ each period to its owner. Participation in the market requires forgoing other potential investment opportunities. An exogenous per period opportunity cost is denoted $c_{l} \in(0, d)$. An agent that owns an asset is subject to a random shock that increases the cost of market participation to $c_{h}>c_{l}$. This additional holding cost could reflect, for example, a need for liquidity. Conditional on holding an asset, the liquidity shock arrives with probability $\delta$ each period. Once an agent experiences this shock, his cost of market participation will remain high forever. This captures the idea that some asset holders might develop the desire to sell, which generates churning in the market.

Trading process. Ownership of the asset can be transferred in a decentralized market subject to search frictions described below. Once the asset is sold, the seller exits the market with the revenue from the sale. Traders therefore transition to a

\footnotetext{
${ }^{7}$ This simplifies the bargaining problem and avoids having to solve for a more complicated distribution of asset holdings in equilibrium.
} 
different trading status depending on their asset holdings and their cost of market participation. There are three different stages that occur sequentially: (i) buyers $(n)$ do not own an asset; (ii) owners $(m)$ have the asset and do not incur additional holding costs; and (iii) sellers $(s)$ have the asset, but have experienced the liquidity shock and face a high cost of market participation. Denote the measure of traders of different types at time $t$ by $n_{t}, m_{t}$, and $s_{t}$.

Let $\left\{V_{t}^{n}, V_{t}^{m}, V_{t}^{s}\right\}$ denote the expected present discounted values associated with buying, owning, and selling the asset at time $t$. These values represent the solution to the system of Bellman equations derived below. The net surplus from a transaction at time $t$ at price $P$ is therefore $V_{t}^{m}-V_{t}^{n}-P$ for a buyer, and $P-V_{t}^{s}$ for a seller.

Search and matching. The meeting process between buyers and sellers is subject to frictions, but search can be directed by advertised prices in the following sense: all traders have the opportunity to publicly post a price. Prices displayed by buyers and sellers are referred to as bid and ask prices, respectively. Traders can observe all publicly advertised prices and may search for a trading partner with a particular bid or ask price. For simplicity, traders cannot simultaneously post a price and actively search. $^{8}$

Let $p \in \mathbb{R}_{+}$denote a posted price, and let $s_{t}(a, p)$ and $n_{t}(a, p)$ (or $n_{t}(b, p)$ and $s_{t}(b, p)$ ) indicate the numbers of traders posting and searching for ask price (or bid price) $p$. The first argument indicates whether the advertised price is a seller's ask price or buyer's bid price. Buyers and sellers are matched according to a bilateral meeting technology. Let $\mathcal{M}\left(n_{t}(i, p), s_{t}(i, p)\right)$ denote the number of matched buyerseller pairs at time $t$ in submarket $(i, p) \in\{a, b\} \times \mathbb{R}_{+}$. The matching function $\mathcal{M}$ is non-decreasing in both arguments, exhibits constant returns to scale and satisfies

\footnotetext{
${ }^{8}$ While it may be interesting to consider the possibility that traders both post a price and search, doing so would require a substantially more complicated matching process and method of price determination.
} 
the condition that the number of matches is less than the number of traders on the short side of the market, $\mathcal{M}(n, s) \leq \min \{n, s\}$. It is convenient to define $\theta_{t}(i, p) \equiv$ $n_{t}(i, p) / s_{t}(i, p)$ as the ratio of buyers to sellers participating in submarket $(i, p)$, which is referred to as market tightness. Given the properties of $\mathcal{M}$, the probability that a buyer will meet a seller in period $t$ may be written as a function of $\theta_{t}(i, p)$ :

$$
\lambda\left(\theta_{t}(i, p)\right)=\frac{\mathcal{M}\left(n_{t}(i, p), s_{t}(i, p)\right)}{n_{t}(i, p)}=\mathcal{M}\left(1,1 / \theta_{t}(i, p)\right) .
$$

Let $\gamma\left(\theta_{t}(i, p)\right)$ denote the analogous matching probability from the perspective of a seller:

$$
\gamma\left(\theta_{t}(i, p)\right)=\frac{\mathcal{M}\left(n_{t}(i, p), s_{t}(i, p)\right)}{s_{t}(i, p)}=\mathcal{M}\left(\theta_{t}(i, p), 1\right)=\theta_{t}(i, p) \lambda\left(\theta_{t}(i, p)\right)
$$

Traders direct their search by posting or targeting a particular price given their beliefs about matching probabilities. The function for market tightness, $\theta_{t}$, summarizes the perceived price posting strategies and search behavior of other traders.

Assumption 1. The function $\gamma:[0, \infty] \rightarrow[0,1]$ is twice continuously differentiable, increasing, concave, and satisfies the boundary conditions $\gamma(0)=0$ and $\gamma(\infty)=1$.

Price determination It is assumed that buyers and sellers have the capacity to commit to honoring their posted price. A price poster's counterparty, on the other hand, has not publicly announced any such commitment and therefore reserves the right to negotiate. Absent agreement to transact at the advertised price, the transaction price of the asset is determined by means of an alternating offer bargaining game. Following Binmore, Rubinstein, and Wolinsky (1986), the buyer and seller bargain strategically when there is a perceived risk that the bargaining process will terminate in disagreement between offers. The trader rejecting the posted price is the first to make a counteroffer. 
For example, suppose the seller has advertised ask price $p$ which the buyer refuses to pay. In the first round of negotiations, the buyer offers $p_{1}$ which the seller can either accept or reject. If the offer is accepted, the bargaining game ends and ownership of the asset is transferred to the buyer in exchange for payment $p_{1}$. If $p_{1}$ is rejected, negotiations breakdown with probability $1-\exp (-(1-\phi) \Delta)$ and both parties continue searching/waiting for a trading partner the following period. If bargaining continues, the seller proposes a price $p_{2}$ to be accepted or rejected by the buyer. If rejected, negotiations can again be terminated, this time with probability $1-\exp (-\phi \Delta)$. The bargaining game continues indefinitely until either negotiations are aborted or a mutually agreeable offer is proposed and accepted. Figure 1 displays the timing of the alternating offer bargaining game. Figure 2 displays the negotiation process when a seller contacts a buyer that advertised a bid price.

Consider the limiting subgame perfect equilibrium outcome by letting the length of the bargaining rounds, $\phi \Delta$ and $(1-\phi) \Delta$, decrease to zero for a given $\phi \in[0,1]$, as in Binmore (1980) and Binmore, Rubinstein, and Wolinsky (1986). This allows the dynamic strategic model of bargaining to be collapsed into a single time period of the dynamic search model. Here, the perceived risk of breakdown can be thought of as a proxy for commitment; the higher (lower) is $\phi$, the higher (lower) is the seller's (buyer's) commitment to his offer as the final offer, even if rejected. By taking the limit as $\Delta \rightarrow 0$, what is important is the bargainer's relative power of commitment, even though neither trader can terminate the bargaining process in disagreement with positive probability. ${ }^{9}$

Search and bargaining models of frictional markets typically assume that the bargaining strength of the seller relative to that of the buyer is constant across all matched buyer-seller pairs. More generally, there might be pre-match uncertainty

\footnotetext{
${ }^{9}$ This interpretation follows Schelling's (1956) views on strategic bargaining and the model based on commitment in Section 8.7 of Myerson (1991).
} 


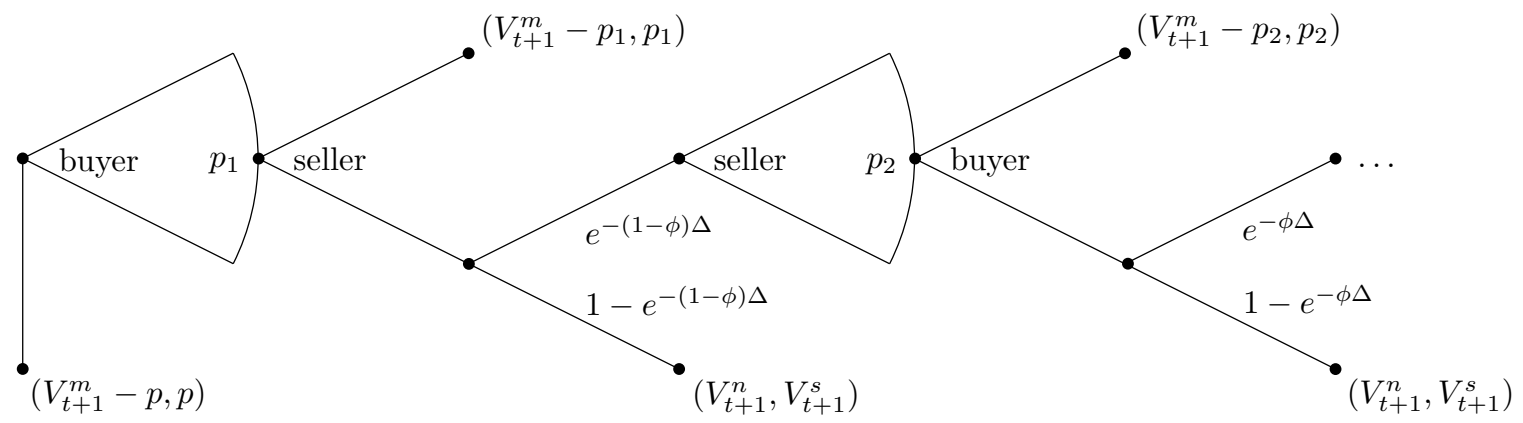

Figure 1: Price determination when the seller is contacted by a buyer.

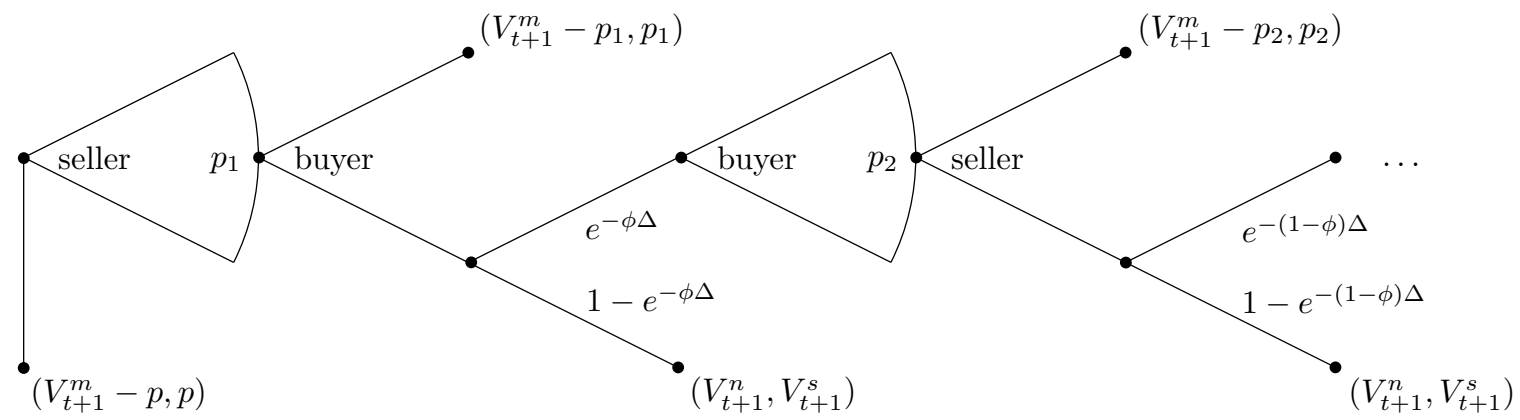

Figure 2: Price determination when the buyer is contacted by a seller.

about traders' tenacity at the bargaining table in terms of their capacity to commit to offers. In other words, an individual's bargaining prowess likely varies over time and may depend on the specific characteristics of the bargaining opponent. To incorporate these ideas in a simple and tractable manner, let $\phi$ be the realization of a match-specific random variable, observed by both parties.

Assumption 2. The match-specific bargaining parameter is a random variable with cumulative distribution function $F$ satisfying $F(0)=0$ and $F(1)=1$.

The counterparty in the match can agree to transact at the posted price, but retains the right to negotiate depending upon the realized division of bargaining power, $\phi$. If actively searching traders are strategic about when to negotiate, then an advertising trader can conceivably set a bid or ask price as a commitment to 
an initial or preemptive offer in the bargaining game to more effectively attract a potential trading partner. The unpredictability of the bargaining outcome introduces uncertainty about whether a counterparty will accept the posted terms of trade or instead elect to negotiate. In that sense, quoting ask price $p$ can be viewed as offering a call option to the buyer with strike price $p$, whereas a bid price is akin to a put option.

Free entry. It is worthwhile to enter the market as a buyer at time $t$ as long as the expected present discounted value associated with searching to buy an asset, $V_{t}^{n}$, is positive.

\section{$3 \quad$ Equilibrium}

To establish links between posted prices, matching probabilities and transaction prices, this section characterizes the optimal strategies and equilibrium outcomes.

Bargaining outcome. The following lemma combines Propositions 3 and 5 in Binmore, Rubinstein, and Wolinsky (1986). In the absence of agreement to transact at the posted price, it states that the unique subgame perfect equilibrium outcome of the bargaining game converges to the asymmetric generalization of the Nash solution. The net surplus captured by the seller is a fixed share of the total surplus from a transaction, where the surplus-splitting rule is determined by the seller's relative bargaining strength, $\phi$.

Lemma 1. If the buyer rejects the ask price and engages the seller in the bargaining game, there exists a unique subgame perfect equilibrium. The existence and uniqueness results similarly hold if the seller rejects the posted bid price and engages the buyer in the bargaining game. In the limit as $\Delta \rightarrow 0$, the equilibrium outcome at time $t$ in 
both cases is

$$
\hat{p}_{t}=V_{t+1}^{s}+\phi\left(V_{t+1}^{m}-V_{t+1}^{n}-V_{t+1}^{s}\right)
$$

The pre-match expected bargaining outcome at time $t$, ignoring posted prices, is therefore

$$
\mathbb{E}\left[\hat{p}_{t}\right]=V_{t+1}^{s}+\left(V_{t+1}^{m}-V_{t+1}^{n}-V_{t+1}^{s}\right) \int_{0}^{1}[1-F(\phi)] d \phi
$$

where the integral in the last term is the expected value of the bargaining parameter.

Occurrence of negotiation. Upon meeting a seller asking price $p$, the buyer observes realization $\phi$ and anticipates the outcome of the bargaining game. The buyer's optimal strategy is to bargain if $\hat{p}_{t}<p$ and to accept $p$ otherwise. When a seller targets a buyer offering bid price $p$, the seller elects to negotiate so as to collect $\max \left\{p, \hat{p}_{t}\right\}$. These optimal strategies are stated in the following lemma using the solution to the bargaining problem from Lemma 1.

Lemma 2. An ask price of $p$ is paid by the buyer without further negotiations whenever

$$
\phi \geq \frac{p-V_{t+1}^{s}}{V_{t+1}^{m}-V_{t+1}^{n}-V_{t+1}^{s}} \equiv \Phi_{t}(p),
$$

whereas a bid price of $p$ is accepted by the seller whenever $\phi \leq \Phi_{t}(p)$.

Let $P_{t}(i, p)$ denote the expected transaction price in a buyer-seller match when the posted price is $p$, where $i \in\{a, b\}$ indicates whether $p$ is an ask price posted by the seller or a bid price posted by a buyer. Expected transaction prices are computed taking into account the decision about when to initiate ex post negotiations (Lemma 2) and the anticipated outcome of the bargaining game (Lemma 1), given the distribution function $F$ which governs the division of bargaining power. When a seller posts price $p$, the expected transaction price is $P_{t}(a, p)=\mathbb{E}\left[\min \left\{p, \hat{p}_{t}\right\}\right]$, or

$$
P_{t}(a, p)=p-\left(V_{t+1}^{m}-V_{t+1}^{n}-V_{t+1}^{s}\right) \int_{0}^{\Phi_{t}(p)} F(\phi) d \phi
$$


When a seller targets a buyer with bid price $p$, the expected price conditional on a match is $P_{t}(b, p)=\mathbb{E}\left[\max \left\{p, \hat{p}_{t}\right\}\right]$, or

$$
P_{t}(b, p)=p+\left(V_{t+1}^{m}-V_{t+1}^{n}-V_{t+1}^{s}\right) \int_{\Phi_{t}(p)}^{1}[1-F(\phi)] d \phi
$$

The expected transaction price, given by $P_{t}(i, p)$ according to $(6)$ and $(7)$, is depicted graphically in Figure 3 to illustrate some important properties summarized in the following lemma.

Lemma 3. (i) The functions $p \mapsto P_{t}(a, p)$ and $p \mapsto P_{t}(b, p)$ are continuous on $\mathbb{R}_{+}$; (ii) $p \mapsto P_{t}(a, p)$ is increasing in $p$ on $\left[0, V_{t+1}^{m}-V_{t+1}^{n}\right)$ and constant when $p \geq V_{t+1}^{m}-V_{t+1}^{n}$, with $P_{t}(a, 0)=0, P_{t}\left(a, V_{t+1}^{s}\right)=V_{t+1}^{s}$ and $P_{t}\left(a, V_{t+1}^{m}-V_{t+1}^{n}\right)=\mathbb{E}\left[\hat{p}_{t}\right] ;$ (iii) $p \mapsto P_{t}(b, p)$ is constant when $p \leq V_{t+1}^{s}$ and increasing in $p$ when $p>V_{t+1}^{s}$, with $P_{t}\left(b, V_{t+1}^{s}\right)=\mathbb{E}\left[\hat{p}_{t}\right]$ and $P_{t}\left(b, V_{t+1}^{m}-V_{t+1}^{n}\right)=V_{t+1}^{m}-V_{t+1}^{n}$; and (iv) the function $P_{t}:\{a, b\} \times \mathbb{R}_{+} \rightarrow \mathbb{R}_{+}$is surjective.

Any expected transaction price below the expected bargaining outcome, $\mathbb{E}\left[\hat{p}_{t}\right]$, can be implemented with an appropriate choice of ask price, and any expected transaction price above can be achieved with the appropriate choice of bid price.

Posted prices, search and free entry. To study the search decisions and price posting problems of buyers and sellers, it is necessary to first derive the Bellman equations for $V_{t}^{m}, V_{t}^{s}$ and $V_{t}^{n}$. The present discounted value of owning the asset at time $t$ is given by

$$
V_{t}^{m}=d-c_{l}+\beta\left[(1-\delta) V_{t+1}^{m}+\delta V_{t+1}^{s}\right]
$$

Equation (8) states that the value of owning the asset is equal to the current dividend, $d$, less the opportunity cost, $c_{l}$, plus the expected present discounted value next period; this will either be the value of maintaining ownership, $V_{t+1}^{m}$, which occurs 


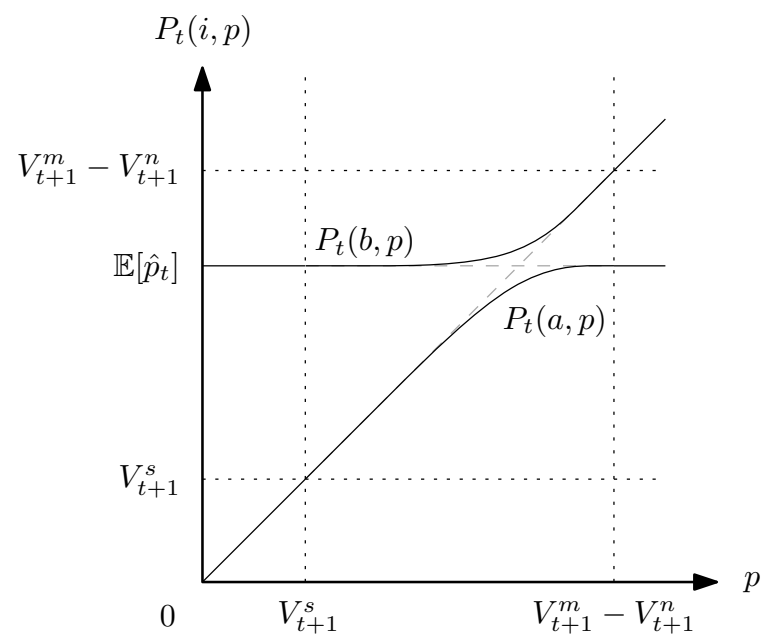

Figure 3: Expected transaction price as a function of the posted price.

with probability $(1-\delta)$, or the value after the liquidity shock, which occurs with probability $\delta$. In this case, the trader captures the present discounted value of selling the asset, $V_{t+1}^{s}$. The values associated with attempts to sell or buy an asset at time $t$ satisfy

$$
\begin{aligned}
V_{t}^{s} & =d-c_{h}+\beta \max _{i \in\{a, b\}, p}\left\{\gamma\left(\theta_{t}(i, p)\right) P_{t}(i, p)+\left(1-\gamma\left(\theta_{t}(i, p)\right)\right) V_{t+1}^{s}\right\} \\
V_{t}^{n} & =-c_{l}+\beta \max _{i \in\{a, b\}, p}\left\{\lambda\left(\theta_{t}(i, p)\right)\left(V_{t+1}^{m}-P_{t}(i, p)\right)+\left(1-\lambda\left(\theta_{t}(i, p)\right)\right) V_{t+1}^{n}\right\},
\end{aligned}
$$

where maximizing with respect to $i \in\{a, b\}$ reflects the choice between price posting and actively searching. Maximizing with respect to $p$ in (9), for example, reflects the choice of ask price for a seller if $i=a$, and the search decision among buyers posting bid prices if $i=b$. In (10) it reflects the choice of bid price or the search decision of a buyer. When there is a match between a buyer and seller, the final price of an asset depends on the equilibrium outcome of the bargaining procedure given realization $\phi$ as well as the optimal renegotiation strategy conditional on the posted price. Traders understand ex ante that their search and price posting decisions affect 
the expected payment (i.e., that $P_{t}(i, p)$ is consistent with equations (6) and (7)). Traders may also perceive that these decisions affect their matching probability via market tightness, $\theta_{t}(i, p)$. The following definition of a directed search equilibrium is helpful for characterizing the latter relationship.

Definition 1. A directed search equilibrium is a sequence of sets of ask prices $\left\{\mathbb{P}_{t}^{a}\right\}_{t=0}^{\infty}$, where $\mathbb{P}_{t}^{a} \subset \mathbb{R}_{+}$; a sequence of sets of bid prices $\left\{\mathbb{P}_{t}^{b}\right\}_{t=0}^{\infty}$, where $\mathbb{P}_{t}^{b} \subset \mathbb{R}_{+}$; a sequence of functions for market tightness $\left\{\theta_{t}\right\}_{t=0}^{\infty}$, where $\theta_{t}:\{a, b\} \times \mathbb{R}_{+} \rightarrow \mathbb{R}_{+} \cup\{\infty\}$; and a bounded sequence of values $\left\{V_{t}^{n}, V_{t}^{m}, V_{t}^{s}\right\}_{t=0}^{\infty}$ satisfying the following:

(i) Buyers' optimal price posting and search with free entry at each time $t$ : given $V_{t+1}^{n}$ and $V_{t+1}^{m}$, for $i \in\{a, b\}$ and $p \in \mathbb{R}_{+}$,

$$
-c_{l}+\beta\left[\lambda\left(\theta_{t}(i, p)\right)\left(V_{t+1}^{m}-P_{t}(i, p)\right)+\left(1-\lambda\left(\theta_{t}(i, p)\right)\right) V_{t+1}^{n}\right] \leq V_{t}^{n},
$$

with equality if either $p \in \mathbb{P}_{t}^{i}$ or $\lambda\left(\theta_{t}(a, p)\right)<1$, where $V_{t}^{n}=0$.

(ii) The value of asset ownership at each time $t$ : given $V_{t+1}^{m}$ and $V_{t+1}^{s}, V_{t}^{m}$ is given by

$$
V_{t}^{m}=d-c_{l}+\beta\left[(1-\delta) V_{t+1}^{m}+\delta V_{t+1}^{s}\right] .
$$

(iii) Sellers' optimal price posting and search at each time $t$ : given $V_{t+1}^{s}$, for $i \in\{a, b\}$ and $p \in \mathbb{R}_{+}$,

$$
d-c_{h}+\beta\left[\gamma\left(\theta_{t}(i, p)\right) P_{t}(i, p)+\left(1-\gamma\left(\theta_{t}(i, p)\right)\right) V_{t+1}^{s}\right] \leq V_{t}^{s},
$$

with equality if $\gamma\left(\theta_{t}(b, p)\right)<1$, where $V_{t}^{s}$ is given by

$$
V_{t}^{s}=d-c_{h}+\beta \max _{i \in\{a, b\}, p \in \mathbb{P}_{t}^{i}}\left[\gamma\left(\theta_{t}(i, p)\right) P_{t}(i, p)+\left(1-\gamma\left(\theta_{t}(i, p)\right)\right) V_{t+1}^{s}\right]
$$

or $V_{t}^{s}=d-c_{h}+\beta V_{t+1}^{s}$ if $\mathbb{P}_{t}^{a}$ and $\mathbb{P}_{t}^{b}$ are both empty.

Optimal price posting and search ensures that each trader maximizes the value of market participation by either passively directing search or actively seeking a trading partner given the equilibrium relationships between market tightness and posted 
prices. Free entry into the market drives the present discounted value of market participation for buyers to zero. Parts (i) and (iii) of Definition 1 uphold that perceived market tightness is consistent with a notion of subgame perfection: the function $p \mapsto \theta_{t}(b, p)$ is such that sellers achieve $V_{t}^{s}$ for any bid price including those not posted in equilibrium, while $p \mapsto \theta_{t}(a, p)$ is consistent with buyers' indifference about market participation for any possible ask price. ${ }^{10}$ The optimal use of the public medium for advertised prices is the novel part of the directed search equilibrium; it requires that buyers and sellers engage in price posting if and only if it is worthwhile to do so given the strategies of other traders as represented by the function for market tightness.

The recursive structure of the directed search equilibrium allows me to define a directed search equilibrium at time $t$ : given any $V_{t+1}^{n} \in \mathbb{R}_{+}, V_{t+1}^{m} \in \mathbb{R}_{+}$, and $V_{t+1}^{s} \in \mathbb{R}_{+}$, $\left\langle\mathbb{P}_{t}^{a}, \mathbb{P}_{t}^{b}, \theta_{t}, V_{t}^{n}, V_{t}^{m}, V_{t}^{s}\right\rangle$ is a directed search equilibrium at time $t$ if it satisfies conditions (i), (ii) and (iii) of Definition 1 for time $t$. The following lemma establishes existence of directed search equilibrium at time $t$ and provides a partial characterization.

Lemma 4. Given any $V_{t+1}^{n} \in \mathbb{R}_{+}, V_{t+1}^{m} \in \mathbb{R}_{+}$, and $V_{t+1}^{s} \in \mathbb{R}_{+}$satisfying

$$
\beta V_{t+1}^{n}<c_{l}<\beta \lambda(0)\left(V_{t+1}^{m}-V_{t+1}^{n}-V_{t+1}^{s}\right)
$$

there exists a directed search equilibrium at time $t$. If $\left\langle\mathbb{P}_{t}^{a}, \mathbb{P}_{t}^{b}, \theta_{t}, V_{t}^{n}, V_{t}^{m}, V_{t}^{s}\right\rangle$ is a directed search equilibrium at time $t$, then any $p \in \mathbb{P}_{t}^{i}$ for $i \in\{a, b\}$ yields market

\footnotetext{
${ }^{10}$ If $p$ is such that a seller cannot achieve $V_{t}^{s}$ for any finite buyer-seller ratio, then $\theta_{t}(b, p)=\infty$. Similarly, $\theta_{t}(a, p)=0$ if the expected discounted value of searching among sellers posting ask price $p$ is negative for any positive buyer-seller ratio.
} 
tightness $\theta_{t}(i, p)=\theta_{t}^{*}$ and expected transaction price $P_{t}(i, p)=P_{t}^{*}$ satisfying

$$
\begin{aligned}
c_{l} & =\beta\left[\lambda\left(\theta_{t}^{*}\right)\left(V_{t+1}^{m}-P_{t}^{*}\right)+\left(1-\lambda\left(\theta_{t}^{*}\right)\right) V_{t+1}^{n}\right] \\
P_{t}^{*} & =V_{t+1}^{s}+\eta\left(\theta_{t}^{*}\right)\left(V_{t+1}^{m}-V_{t+1}^{n}-V_{t+1}^{s}\right)
\end{aligned}
$$

where $\eta\left(\theta_{t}^{*}\right)=1-\theta_{t}^{*} \gamma^{\prime}\left(\theta_{t}^{*}\right) / \gamma\left(\theta_{t}^{*}\right)$.

There is an equilibrium market tightness for any price posted in equilibrium, denoted $\theta_{t}^{*}$, and the expected transaction price is $P_{t}^{*}$ in any buyer-seller match. Equation (11) is the free entry condition, and equation (12) designates the equilibrium division of the match surplus (in expectation) between buyer and seller. Lemma 4 does not directly identify the set of prices advertised in equilibrium nor the set of traders posting prices. Instead, Lemma 4 determines the expected final price and market tightness (or market liquidity) in a directed search equilibrium. The details of the bargaining process determine how this equilibrium outcome is implemented. In some circumstances, ask prices may be useful for directing search. In other instances, bid prices may play a strategic role. Any price posted in equilibrium, however, must satisfy $P_{t}(i, p)=P_{t}^{*}$. That is, any price advertised in equilibrium must deliver an expected transaction price consistent with both (i) the directed search equilibrium outcome (Lemma 4), and (ii) the bargaining outcome (Lemmas 1 and 2). This requirement determines $\mathbb{P}_{t}^{a}$ and $\mathbb{P}_{t}^{b}$. In particular, any $p \in \mathbb{P}_{t}^{a}$ must satisfy (6) and (12), or

$$
\int_{0}^{\Phi_{t}(p)}[1-F(\phi)] d \phi=\eta\left(\theta_{t}^{*}\right)
$$

whereas any $p \in \mathbb{P}_{t}^{b}$ must satisfy (7) and (12), or

$$
\int_{\Phi_{t}(p)}^{1} F(\phi) d \phi=1-\eta\left(\theta_{t}^{*}\right) .
$$


The following proposition addresses uniqueness of the equilibrium posted price and establishes a link between the details of the ex post bargaining procedure and the direction of search (i.e., the side of the market actively searching) in equilibrium.

Proposition 1. If $P_{t}^{*} \neq \mathbb{E}\left[\hat{p}_{t}\right]$ or, equivalently, $\eta\left(\theta_{t}^{*}\right) \neq \int_{0}^{1} \phi d F$, then $\mathbb{P}_{t}^{a} \cup \mathbb{P}_{t}^{b}$ is a singleton. $\mathbb{P}_{t}^{b}$ is empty if $\eta\left(\theta_{t}^{*}\right)<\int_{0}^{1} \phi d F$, whereas $\mathbb{P}_{t}^{a}$ is empty if $\eta\left(\theta_{t}^{*}\right)>\int_{0}^{1} \phi d F$.

Sellers post prices to compete for buyers whenever their expected bargaining strength is too high otherwise. If instead sellers' expected bargaining strength is too low, then buyers post prices in an effort to compete for sellers. The theory therefore predicts price posting on the side of the market with too much bargaining power. The intuition is that anticipated bargaining fortitude is not advantageous in a directed search environment: traders prefer to weaken their position by posting a price to more effectively attract a trading partner. Note that if $P_{t}^{*}=\mathbb{E}\left[\hat{p}_{t}\right]$ or, equivalently, $\eta\left(\theta_{t}^{*}\right)=\int_{0}^{1} \phi d F$, there are no incentives for buyers or sellers to direct search with price posting in equilibrium, although meaningless prices may nonetheless be posted by either side of the market (e.g., a bid price below $\left.V_{t+1}^{s}\right)$. In all other circumstances, search is directed and the equilibrium posted price is unique, given that traders are ex ante identical and assets are homogeneous.

Distribution of traders. The total number of sellers evolves according to

$$
s_{t+1}=s_{t}-\gamma\left(\theta_{t}^{*}\right) s_{t}+\delta m_{t}
$$

Furthermore, since every owner and every seller holds exactly one asset, the total number of owners and sellers must equal the total number of assets in the economy:

$$
m_{t}+s_{t}=A \text {. }
$$


Steady state equilibrium. This market has a steady state equilibrium in which all values and prices are constant over time and the distribution of traders across states is stationary.

Definition 2. The steady state equilibrium for this market can be described by a set of values, $\left\{V^{n}, V^{m}, V^{s}\right\}$; market tightness, $\theta$; an expected transaction price, $P$; sets of advertised prices, $\mathbb{P}^{a}$ and $\mathbb{P}^{b}$; and a distribution of traders across states $\{n, m, s\}$ such that:

(i) values $\left\{V^{n}, V^{m}, V^{s}\right\}$ satisfy

$$
\begin{aligned}
V^{n} & =0 \\
V^{m} & =\frac{d-c_{l}-\beta \delta\left[V^{m}-V^{s}\right]}{1-\beta} \\
V^{s} & =\frac{d-c_{h}+\beta \gamma(\theta) \eta(\theta)\left[V^{m}-V^{s}\right]}{1-\beta}
\end{aligned}
$$

(ii) market tightness is the result of free entry: $\theta$ satisfies

$$
c_{l}=\beta \lambda(\theta)(1-\eta(\theta))\left[V^{m}-V^{s}\right]
$$

(iii) the expected transaction price is consistent with directed search: $P$ satisfies

$$
P=V^{s}+\eta(\theta)\left[V^{m}-V^{s}\right]
$$

(iv) traders advertise and negotiate prices strategically: any $p \in \mathbb{P}^{a}$ satisfies

$$
\int_{0}^{\frac{p-V^{s}}{V^{m}-V^{s}}}[1-F(\phi)] d \phi=\eta(\theta),
$$

whereas any $p \in \mathbb{P}^{b}$ satisfies

$$
\int_{\frac{p-V^{s}}{V^{m}-V^{s}}}^{1} F(\phi) d \phi=1-\eta(\theta) ; \text { and }
$$


(v) the distribution of traders across states is stationary: $\{m, s, n\}$ satisfy

$$
\begin{aligned}
\mathcal{M}(n, s) & =\delta m \\
m+s & =A \\
n & =\theta s .
\end{aligned}
$$

Equations (22) and (23) in part (iv) of Definition 2 relate posted prices to the distribution function $F$ governing the stochastic division of bargaining strength. A first-order stochastic dominant shift in $F$, for example, whereby $F(\phi)$ decreases for all $\phi \in(0,1)$, causes the steady state equilibrium posted price to decline, regardless of the side of the market posting. The distribution of negotiated outcomes in this case becomes more favorable for sellers. Restoring the directed search equilibrium relationship between the expected final price and matching probabilities requires a drop in posted prices. A mean preserving spread in $F$, on the other hand, affects bid and ask prices asymmetrically. In an equilibrium with ask prices, a mean preserving spread means that bargaining can lead to lower prices, but the option of paying the ask price limits the correspond effect at the high end of the final price distribution. It follows that ask prices increase. A similar argument from the perspective of buyers leads to the conclusion that bid prices decrease with a mean preserving spread in $F$. These comparative statics are summarized in the following proposition.

Proposition 2. Any $p \in \mathbb{P}^{a} \cup \mathbb{P}^{b}$ decreases with a first-order stochastic dominant shift in $F$. Any $p \in \mathbb{P}^{a}$ increases with a mean preserving spread in $F$, whereas any $p \in \mathbb{P}^{b}$ decreases with a mean preserving spread in $F$.

It should also be noted that a discrete change in $F$ can cause price posting to switch from one side of the market to the other. For example, a first-order stochastic dominant shift in $F$ can push the equilibrium bid price down to $V^{s}$, at which point any further shift in $F$ that favors the supply side of the market prompts sellers to post ask prices in equilibrium. 
Constrained efficiency. To address constrained efficiency, consider a social planner that aims to maximize the welfare of market participants subject to search frictions and the cost of market participation. At each time $t$, the constrained planner first designates the number of demand-side participants, $n_{t}$, to maximize total social surplus:

$$
\max _{\left\{n_{t}\right\}_{t=0}^{\infty}} \sum_{t=0}^{\infty} \beta^{t}\left[m_{t}\left(d-c_{l}\right)+s_{t}\left(d-c_{h}\right)-n_{t} c_{l}\right]
$$

subject to the law of motion for the number of sellers, $s_{t+1}=s_{t}-\gamma\left(\theta_{t}\right) s_{t}+\delta m_{t}$, and the aggregation condition, $m_{t}+s_{t}=A$, given the definition $\theta_{t}=n_{t} / s_{t}$, for all $t$. The social planner then allocates surplus among participating traders subject to participation constraints. Given risk-neutrality, however, the allocation of surplus among traders does not affect total social surplus and hence does not affect the planner's choice of $n_{t}$. The following proposition states that the decentralized steady state equilibrium allocation coincides with a solution to the constrained planner's problem.

Proposition 3. The steady state equilibrium for this market is constrained efficient.

A solution to the constrained social planner's problem allocates surplus among market participants such that present discounted values equal the steady state equilibrium values, $\left\{V^{n}, V^{m}, V^{s}\right\}$. In that case, the social benefit associated with a marginal increase in the number of traders is $\beta \gamma^{\prime}(\theta)\left[V^{m}-V^{s}\right]$, whereas the marginal social cost is $c_{l}$. The steady state equilibrium free entry condition equates the social marginal costs and benefits of market participation because the price determination mechanism assigns to each prospective buyer their marginal contribution (in expectation) to the match:

$$
c_{l}=\beta \lambda(\theta)\left[V^{m}-P\right]=\beta \lambda(\theta)[1-\eta(\theta)]\left[V^{m}-V^{s}\right]=\beta \gamma^{\prime}(\theta)\left[V^{m}-V^{s}\right] .
$$

This is a familiar condition for constrained efficiency in models with search frictions 
(Mortensen, 1982b; Hosios, 1990).

The constrained efficient level of market activity thus arises in equilibrium despite the generic inefficiencies of the bargaining procedure and limited commitment to posted prices. An important feature of the environment for this result is universal access to the price posting technology. When $\eta\left(\theta^{*}\right)<\int_{0}^{1} \phi d F$, the expected division of bargaining power favors the seller. In the absence of posted prices, too few buyers would enter the market (relative to the constrained efficient allocation). A seller would be willing to give up some of their (expected) surplus in exchange for a higher matching probability, which is accomplished by posting an ask price low enough to incentivize buyers to direct their search. If instead $\eta\left(\theta^{*}\right)>\int_{0}^{1} \phi d F$, sellers capture too little of the expected surplus in negotiations. Consequently, there would be excessive market entry in the absence of posted prices relative to a constrained efficient allocation. Sellers sensibly refrain from quoting ask prices in these circumstances because such a strategy could only further diminish their expected gains. Instead, buyers respond optimally to the relative scarcity of sellers by posting sufficiently attractive bid prices to improve the probability of a match. Bid prices are thus posted by the demand side of the market in equilibrium and sellers actively search for buyers such that constrained efficiency is upheld. Advertising capabilities on both sides of the market with search direction determined endogenously are essential for achieving generic constrained efficiency.

\section{Examples and Discussion}

Two examples of steady state equilibria are presented in this section to illustrate the positive implications of the theoretical model. The first example illustrates the implications of Propositions 1 and 2, which relate the details of the bargaining process 
to both posted prices and the direction of search. The second example abstracts from uncertainty in the division of bargaining power to show that the mere possibility of bilateral price negotiations can determine the direction of search even when bargaining is never observed in equilibrium.

\subsection{Simulated Examples}

Example 1. This first example illustrates the implications of bargaining uncertainty for the incidence of price negotiations and dispersion in transaction prices. Suppose that $\phi$ is the match-specific realization of a triangular-distributed random variable with minimum and maximum values 0 and 1 . If the expected value of the random bargaining parameter equals $\eta(\theta)$ there is no role for advertised prices in directing search $^{11}$ and the distribution of negotiated prices mirrors the distribution of the random bargaining parameter. Whenever the expected value of diverges from $\eta(\theta)$, either buyers or sellers face incentives to post prices. The unique equilibrium posted price leads to a truncated distribution of final prices to exactly maintain an expected price of $P \equiv V^{s}+\eta(\theta)\left[V^{m}-V^{s}\right]$. To illustrate this graphically, Figure 4 plots the distributions of prices corresponding to different modal values of the triangular distribution. ${ }^{12}$ Figure 4a plots scenarios in which ask prices arise in equilibrium; Figure 4b plots equilibria with bid prices. Note that the implications for posted prices correspond to the first comparative static exercise of Proposition 2.

Example 2. This second example focuses on the special case with no uncertainty in the division of bargaining power to show that the equilibrium outcomes can repli-

\footnotetext{
${ }^{11}$ The expected outcome of the bargaining game in this case satisfies the directed search equilibrium relationship between expected price and market tightness in the absence of posted prices. Neither bid nor ask prices are thus required to direct search.

${ }^{12}$ The following parameter values were used to generate Figure $4: A=1, \beta=0.99, \delta=0.05$, $d=c_{h}=1$, and $c_{l}=0.45$ so that $\eta(\theta)=0.5$. The bargaining parameter is triangular-distributed with lower limit 0, upper limit 1 , and five different modes: $\{0.35,0.47,0.50,0.53,0.65\}$. The matching function is $\mathcal{M}(n, s)=n s /(n+s)$.
} 


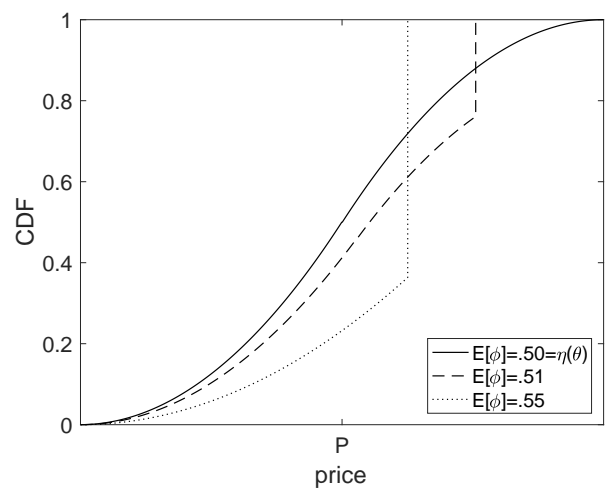

(a) equilibria with ask prices

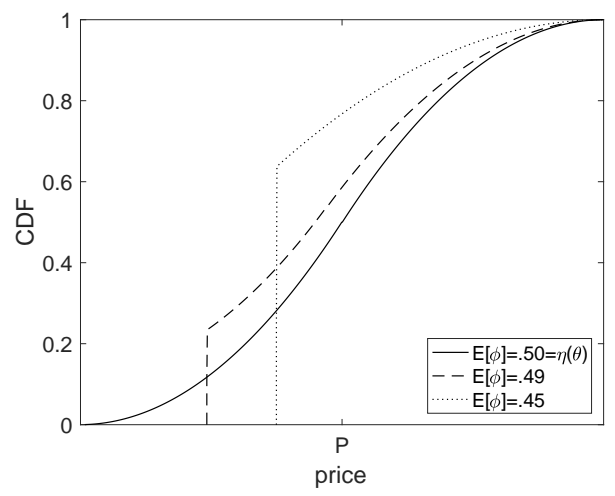

(b) equilibria with bid prices

Figure 4: Distributions of final prices in markets with bargaining uncertainty (Example 1).

cate those of a random search model with ex post bargaining, or those of a competitive search model with full commitment to posted prices. To shut down variation in the division of the match surplus, let $\phi$ be constant across all matched buyer-seller pairs.

If $\phi=\eta(\theta)$, once again posted prices play no role in directing search. The outcome of the bargaining game, $\hat{p}=V^{s}+\phi\left[V^{m}-V^{s}\right] \equiv P$, satisfies the directed search equilibrium relationship between price and market tightness. Search is not directed by posted prices in the sense that only meaningless prices (e.g., a bid price below $\hat{p}$ or an ask price above $\hat{p}$ ) can crop up in equilibrium. Consequently, ex post bargaining can occur in equilibrium between every matched buyer and seller, and the unique equilibrium price corresponds to the asymmetric generalization of the Nash solution. Random search with bargaining is thus a knife-edge special case of the model.

If instead $\phi$ is fixed at some value not equal to $\eta(\theta)$, bargaining is an out-ofequilibrium phenomenon. The posted price, $p=V^{s}+\eta(\theta)\left[V^{m}-V^{s}\right] \equiv P$, is unique, as per Proposition 1, and every asset trades at the posted price. The properties of this equilibrium resemble those of a model of directed search with full commitment to the posted price. The novel feature relative to the standard model, however, is that 
search direction is endogenously determined by the prospect of bilateral bargaining. Sellers all post the equilibrium price if and only if $\phi>\eta(\theta)$.

\subsection{Discussion of Modeling Assumptions}

Before turning to an extension and application of the theory, I provide a brief discussion of some of the modeling assumptions.

Search and matching. The matching function, $\mathcal{M}$, governs the frictional matching process between buyers and sellers. An alternate modeling choice would specify a meeting technology between searchers and price-posters as in Delacroix and Shi (2018). In that case, matching probabilities would depend on the side of the market posting offers, and the matching function could be viewed as capturing the implications of coordination and communication frictions. In the former case, matching probabilities depend only on the ratio of buyers to sellers, which is the specification I consider in this paper. I conjecture, however, that one could obtain a similar set of results and insights with the alternate approach, albeit with slightly different notation and interpretation of several key variables. In fact, the two approaches are equivalent if the matching function is symmetric (i.e., if $\mathcal{M}(n, s)=\mathcal{M}(s, n)$ for all $n, s \geq 0)$. Symmetric telephone-line matching, for instance, provides a suitable matching function between buyers and sellers (namely, $\mathcal{M}(n, s)=n s /(n+s)$ ), but could also be derived as the outcome of a bilateral meeting process between price-posters and active searchers (as in Burdett et al. (1995)).

Stochastic bargaining weights. The random division of bargaining strength is intended to capture (in an ad hoc way) the imperfectly anticipated division of surplus arising from heterogeneity in bargaining skills. Appealing again to the commitmentbased interpretation of strategic bargaining with a risk of terminal disagreement (e.g., Schelling (1956), and Section 8.7 of Myerson (1991)), traders may differ in their 
ability to commit to offers as final offers. A stochastic bargaining parameter would in that case reflect pre-match uncertainty about one's trading partner's strength in negotiations. For convenience and tractability, the division of bargaining strength is modeled simply as a match-specific random variable.

Negotiability of posted prices. When the posted price is rejected by the counterparty, the negotiated outcome splits the match surplus, which depends on the buyer's and seller's continuation values and not the posted terms of trade. In models of search and bargaining more generally, this might call into question the very relevance of negotiable price posting. These prices nonetheless matter in the model presented here; they play a role in directing search (and hence improve market efficiency) despite the fact that ex post price negotiation can render them irrelevant. Their relevance stems from their interpretation as initial preemptive offers in an alternating offer bargaining game.

Other mechanisms, such as non-negotiable price-posting ${ }^{13}$ or auctions, ${ }^{14}$ can also implement the constrained efficient allocation. The appeal of this particular method of price determination is twofold. First, it relaxes somewhat the assumption of commitment to the posted terms of trade. In particular, it does not require commitment by the price poster not to entertain less desirable offers, nor does it require the counterparty to agree to the advertised terms of trade. I have thus demonstrated that the constrained efficient allocation can emerge endogenously in markets with both search frictions and limited commitment. ${ }^{15}$ Second, as I show in Section 5, the mechanism proposed here can generate equilibria with both buyers and sellers posting bid and

\footnotetext{
${ }^{13}$ Montgomery (1991), Peters (1991), and Moen (1997), among others, study directed search in markets with firm commitment to the posted price.

${ }^{14}$ Models of competing auctions that adopt a reserve price interpretation of the posted price include Peters and Severinov (1997), Julien, Kennes, and King (2000), and Albrecht, Gautier, and Vroman (2014).

${ }^{15}$ See footnotes 5 and 6 for references to papers that combine search frictions and limited commitment.
} 
ask prices, respectively, with some transactions occurring above (below) the bid (ask) price and other transactions occurring exactly at the posted price. To my knowledge, such predictions are new and, as discussed in Section 5.2, empirically relevant.

\section{Extension and Empirical Application}

As an illustration of the price-related observations that the model is designed to explain, I compare the set of transaction prices with advertised prices observed in a particular decentralized asset market: namely, the secondary market for standard taxicab licenses (STLs) in Toronto. To accommodate posted prices on both sides of the market, I first extend the model to include heterogeneity among traders. Specifically, I introduce ex post trader heterogeneity by allowing for variation in the severity of the liquidity shock. As illustrated below, the introduction of trader heterogeneity results in dispersion in both posted prices and transaction prices, and permits the coexistence of bid and ask prices in equilibrium.

\subsection{Extension: Heterogeneous Traders}

Upon the arrival of the liquidity shock, suppose the asset owner's holding cost increases from $c_{l}$ to a random draw from a distribution with support $\left\{c_{1}, \ldots, c_{H}\right\}$, where $c_{l}<c_{1}<\cdots<c_{H}$. Let $\left\{\Delta_{1}, \ldots, \Delta_{H}\right\}$ denote the probabilities associated with the possible realizations of the ex post holding cost. The present discounted value of owning the asset at time $t$ is now given by

$$
V_{t}^{m}=d-c_{l}+\beta\left[(1-\delta) V_{t+1}^{m}+\delta \sum_{h=1}^{H} \Delta_{h} V_{t+1}^{s h}\right]
$$


The last term reflects the expected value of selling an asset given the various possibilities in terms of the severity of the shock. Conditional on a liquidity shock, the holding cost increases to $c_{h}$ with probability $\Delta_{h}$, and the value associated with selling the asset at time $t$ satisfies

$$
V_{t}^{s h}=d-c_{h}+\beta \max _{i \in\{a, b\}, p}\left\{\gamma\left(\theta_{t}(i, p)\right) P_{t}^{h}(i, p)+\left(1-\gamma\left(\theta_{t}(i, p)\right)\right) V_{t+1}^{s h}\right\}
$$

Because prices can be negotiated, the expected transaction price depends on the seller's type:

$$
\begin{aligned}
& P_{t}^{h}(a, p)=p-\left(V_{t+1}^{m}-V_{t+1}^{n}-V_{t+1}^{s h}\right) \int_{0}^{\Phi_{t}^{h}(p)} F(\phi) d \phi \\
& P_{t}^{h}(b, p)=p+\left(V_{t+1}^{m}-V_{t+1}^{n}-V_{t+1}^{s h}\right) \int_{\Phi_{t}^{h}(p)}^{1}[1-F(\phi)] d \phi .
\end{aligned}
$$

Finally, the value of trying to buy an asset at time $t$ satisfies

$$
V_{t}^{n}=-c_{l}+\beta \max _{i \in\{a, b\}, p}\left\{\begin{array}{r}
\lambda\left(\theta_{t}(i, p)\right) \sum_{h=1}^{H} \pi_{t}^{h}(i, p)\left(V_{t+1}^{m}-P_{t}^{h}(i, p)\right) \\
+\left(1-\lambda\left(\theta_{t}(i, p)\right)\right) V_{t+1}^{n}
\end{array}\right\} .
$$

In (33), probabilities $\left\{\pi_{t}^{1}(i, p), \ldots, \pi_{t}^{H}(i, p)\right\}$ reflect the endogenously determined composition of sellers in submarket $(i, p)$ at time $t$. In general, buyers are concerned about the type of seller they may encounter because it can affect the bargaining outcome. The steady state equilibrium defined and characterized below, however, features a distinct submarket for each type of seller.

Definition 3. The steady state equilibrium for this market can be described by a set of values, $\left\{V^{n}, V^{m},\left\{V^{s h}\right\}_{h=1}^{H}\right\}$; market tightness by submarket, $\left\{\theta^{h}\right\}_{h=1}^{H}$; expected transaction price by submarket, $\left\{P^{h}\right\}_{h=1}^{H}$; sets of advertised prices, $\mathbb{P}^{a}$ and $\mathbb{P}^{b}$; and a 
distribution of traders across states and submarkets, $m$ and $\left\{n^{h}, s^{h}\right\}_{h=1}^{H}$; such that:

(i) values $V^{n}, V^{m}$, and $\left\{V^{s h}\right\}_{h=1}^{H}$ satisfy

$$
\begin{aligned}
V^{n} & =0 \\
V^{m} & =\frac{d-c_{l}-\beta \delta \sum_{h=1}^{H} \Delta_{h}\left[V^{m}-V^{s h}\right]}{1-\beta} \\
V^{s h} & =\frac{d-c_{h}+\beta \gamma\left(\theta^{h}\right) \eta\left(\theta^{h}\right)\left[V^{m}-V^{s h}\right]}{1-\beta}, \quad h=1, \ldots, H ;
\end{aligned}
$$

(ii) market tightness is the result of free entry: $\left\{\theta^{h}\right\}_{h=1}^{H}$ satisfy

$$
c_{l}=\beta \lambda\left(\theta^{h}\right)\left(1-\eta\left(\theta^{h}\right)\right)\left[V^{m}-V^{s h}\right], \quad h=1, \ldots, H
$$

(iii) the expected transaction price is consistent with directed search: $\left\{P^{h}\right\}_{h=1}^{H}$ satisfy

$$
P^{h}=V^{s h}+\eta\left(\theta^{h}\right)\left[V^{m}-V^{s h}\right], \quad h=1, \ldots, H
$$

(iv) traders advertise and negotiate prices strategically: any $p \in \mathbb{P}^{a}$ satisfies, for some $h \in\{1, \ldots, H\}$,

$$
\int_{0}^{\frac{p-V^{s h}}{V^{m}-V^{s h}}}[1-F(\phi)] d \phi=\eta\left(\theta^{h}\right)
$$

whereas any $p \in \mathbb{P}^{b}$ satisfies, for some $h \in\{1, \ldots, H\}$

$$
\int_{\frac{p-V^{s h}}{V^{m}-V^{s h}}}^{1} F(\phi) d \phi=1-\eta\left(\theta^{h}\right) ; \text { and }
$$

(v) the distribution of traders across states and submarkets is stationary: $m$ and $\left\{s^{h}, n^{h}\right\}_{h=1}^{H}$ satisfy

$$
\begin{aligned}
\mathcal{M}\left(n^{h}, s^{h}\right) & =\delta \Delta_{h} m, \quad h=1, \ldots, H \\
m+\sum_{h=1}^{H} s^{h} & =A \\
n^{h} & =\theta^{h} s^{h}, \quad h=1, \ldots, H .
\end{aligned}
$$

Sellers differ in terms of their motivation to sell which affects their willingness to 
trade off expected price and matching probability. The equilibrium is characterized by a set of active submarkets - one for each seller type. Free entry on the demand side implies buyer indifference across active submarkets. Some submarkets may feature ask prices while others feature bid prices, with some transactions occurring above (below) the bid (ask) price and other transactions occurring at the posted price.

Example 3. A final numerical example is computed such that both buyers and sellers post bid and ask prices, respectively. For this example, three submarkets feature ask prices and three submarkets feature bid prices. In yet another submarket, prices need not be posted because $\eta(\theta)=\int_{0}^{1} \phi d F$. The distributions of advertised and final prices are plotted in Figure 5. ${ }^{16}$ Figure 5a depicts a market in which the stochastic bargaining parameter is triangular-distributed with lower limit 0, upper limit 1 , and mode $1 / 2$. Figure $5 \mathrm{~b}$ removes uncertainty about the division of bargaining strength by setting $\phi=1 / 2$. Notice that, in both cases, ask prices tend to exceed transaction prices, and bid prices are generally even lower.

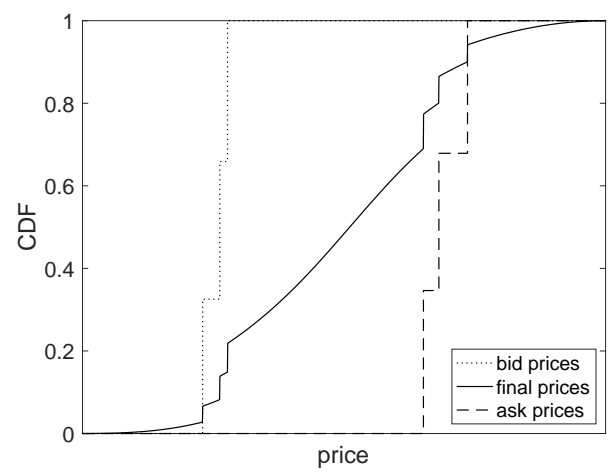

(a) stochastic bargaining power

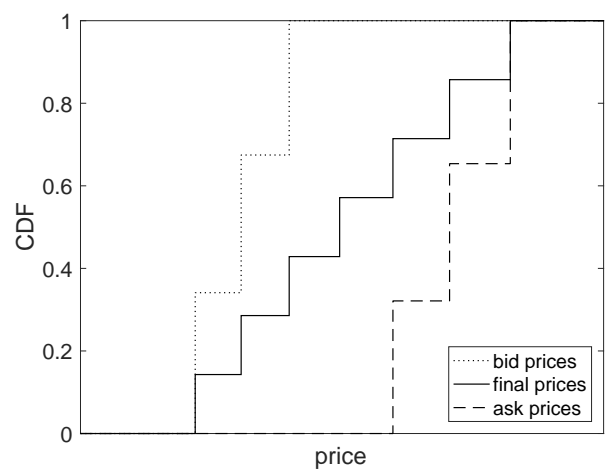

(b) deterministic bargaining power

Figure 5: Price distributions in markets with ex post heterogeneity (Example 3).

\footnotetext{
${ }^{16}$ The parameter values selected to generate Figure 5 are the same as those used in Example 1 (see footnote 12), except that $H=7,\left\{c_{1}, \ldots, c_{7}\right\}=\{0.85,0.90,0.95,1.00,1.05,1.10,1.15\}$, and $\Delta_{h}=1 / 7$ for $h=1, \ldots, 7$.
} 


\subsection{Application: Toronto Standard Taxicab Licenses}

Toronto's taxicab licensing system includes, among other classes of licenses, 3,451 standard taxicab licenses (STLs). This license type can be used for owner-operated taxicabs, leased to a licensed taxicab driver, rented to shift drivers either directly or through intermediaries, or transferred to a new owner by means of a transaction in a decentralized secondary market. The purpose of this section is twofold: (i) to provide evidence that the microstructure of this market corresponds well to the details of the theoretical environment described in Section 2, and (ii) to show that the recent price data align with the positive implications of the theory.

Price posting and bargaining. Buyers and sellers in the secondary market for STLs post classified advertisements on Kijiji.ca, an online classified service owned by eBay, to convey market participation and attract potential trading partners on the opposite side of the market. Online classified advertisement data were collected from March until August 2014. Each ad is one of two types: either an "I am offering" ad for those offering an item for sale, or an "I want" ad for those on the demand side of the market. Many advertisers on both sides of the market publish a price as part of the ad, although some advertisers omit the price and instead select the option to display "Please Contact" after the "Price" heading. The ad also contains the date listed, a title, a message, and sometimes information about the advertiser including address and phone number. Between March and August 2014, messages posted to Kijiji.ca include 57 seller ads and 123 buyer ads. A few of these ads omit prices, but 52 of the 57 ads posted by sellers include ask prices, and 75 of the 123 want ads contain bid prices.

The messages included in the classified advertisements suggest an understanding that posted prices are subject to negotiation. Sellers' ads often include an ask price followed by the phrase "or best offer," or instead provide instructions to "e-mail or 
call to negotiate." Similarly, advertised bid prices are sometimes accompanied by the qualifier "price is negotiable." This terminology points to the possibility of ex post bargaining, which means prices posted to Kijiji.ca are likely not viewed by market participants as take-it-or-leave-it offers.

Transaction prices. Since a transfer of ownership must be approved and comply with the guidelines of the Municipal Code, every transaction is recorded by the city. There were 78 STL ownership transfers between March and August 2014. These include transfers to family members for prices close to zero, ${ }^{17}$ as well as many withinfamily transactions that have prices further from zero but presumably less than market value. In order to focus on market transactions between buyers and sellers that must first search for each other in a decentralized market, STL transfers for amounts less than or equal to $\$ 2$ are excluded from the sample. ${ }^{18}$ Transactions between a buyer and a seller that share a common surname are also excluded from the sample. A total of 49 STL ownership transfers, presumably market transactions, remain after sample restrictions are applied.

Figure 6 displays the distribution of actual transaction prices between March and August, 2014, along with the distributions of bid and ask prices from the classified ads over the same time period. ${ }^{19}$ These empirical distribution functions for advertised and actual prices of STLs mirror, to some extent, the simulated price distributions plotted in Figure 5; advertised bid prices tend to be less than transaction prices, while

\footnotetext{
${ }^{17}$ The City of Toronto's 2012 review of the taxicab industry states that "standard taxicabs cannot be inherited; however, they are often sold to family members for a token amount of 1 dollar."

${ }^{18}$ In the full sample of 78 transactions, there are 2 transactions with a price of $\$ 1$ and 6 transactions with a price of $\$ 2$.

${ }^{19}$ In Figure 6, we restrict the samples of bid and ask prices to those between $\$ 50,000$ and $\$ 250,000$ in an attempt to exclude advertised prices that do not represent meaningful offers. Given that transaction prices for the sample period range from $\$ 62,000$ to $\$ 232,000$, it seems unlikely that bid prices less than $\$ 50,000$ or ask prices above $\$ 250,000$ provide adequate incentives for potential trading partners to direct their search. Including such outlier prices, however, would not affect the qualitative patterns displayed in Figure 6.
} 
advertised ask prices tend to exceed transaction prices. ${ }^{20}$ The qualitative similarities between Figures 5 and 6 suggest that posted prices in the secondary market for STLs affect the incidence of price negotiations and play a role in directing search in the manner proposed in the theory. More generally, the model's ability to replicate the aforementioned characteristics of the STL price distributions is predicated on two important features of the theoretical framework: (i) posted prices on both sides of the market that play a role in directing search, and (ii) the possibility of negotiated increases (discounts) from advertised bid (ask) prices.

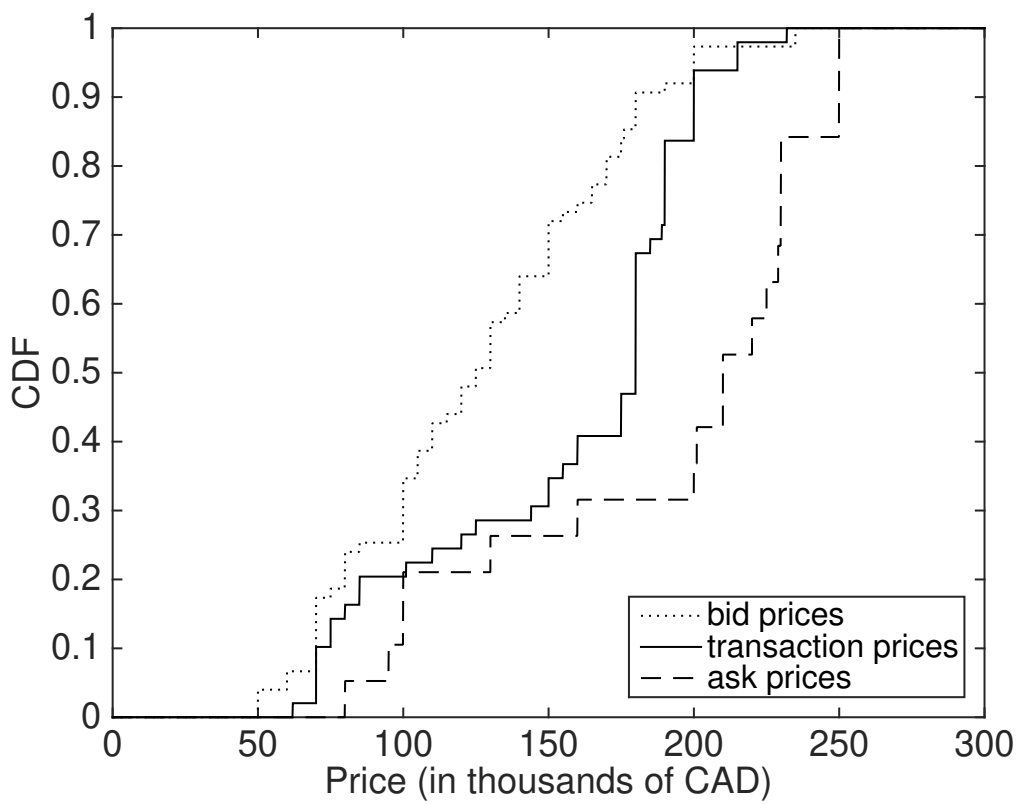

Figure 6: Distributions of bid prices, ask prices and transaction prices.

It is worth remarking that these relationships between posted and final price distributions differ from those predicted by existing models of directed search that adopt

\footnotetext{
${ }^{20}$ Recall that advertised prices were collected from Kijiji.ca, whereas transaction prices were obtained from the City of Toronto's Municipal Licensing and Standards division. It is not possible to link a particular classified advertisement to a specific transaction because trader identities are not revealed/disclosed in both contexts. This unfortunately inhibits further exploration of the relationships between posted prices, transactions prices, and time-on-the-market.
} 
a reserve price interpretation of a posted price. For example, one would expect sellers' posted prices to be lower than transaction prices when there is ex post competition among buyers (e.g., Peters and Severinov, 1997; Julien, Kennes, and King, 2000; and Albrecht, Gautier, and Vroman, 2014). ${ }^{21}$ Similarly, a directed search model that features pre-match price posting by buyers and post-match price demands by competing sellers would imply transaction prices in equilibrium below those advertised by the demand side of the market. It is sometimes assumed that buyers first post initial offers and subsequently increase their bids if other buyers contact the same seller (e.g., Albrecht, Gautier, and Vroman, 2006). Consequently, final prices exceed the offers announced initially by buyers, but by assumption there are no prices posted by the supply side of the market. Similarly, the strategic renegotiation process proposed by Camera and Selcuk (2009) features price posting by only one side of the market. While these directed search models with limited commitment to posted prices predict transaction prices that sometimes differ from those advertised, the implied price distributions do not resemble those observed in the market for STLs. Furthermore, the absence of any heterogeneity in the quality or characteristics of the assets being traded rules out explanations related to idiosyncratic quality and/or costly inspection (e.g., Chen and Rosenthal, 1996a and 1996b; Arnold, 1999; and Lester, Visschers, and Wolthoff, 2017). In this paper, accounting for price distributions like those in Figure 6 requires the opportunity for both sides of the market to post meaningful prices that

\footnotetext{
${ }^{21}$ The search models presented in these papers are appropriate for studying markets that are sufficiently active or unbalanced that multilateral (i.e., many-to-one) matches are common. For example, houses in high-demand neighborhoods often sell above the list price when multiple buyers compete by submitting offers to purchase the same unit. In contrast, the model developed in this paper best describes less active markets where it is unlikely that a buyer or seller will be in contact with more than one potential trading partner at the same time. The model could be extended to account for transactions both above and below the posted price by embellishing the matching technology to include occasional multilateral meetings. For example, in the rare event that several buyers match with a single seller, ex post competition among buyers could result in a transaction price above the seller's ask price. The role of posted prices would remain the same as long as multilateral meetings are sufficiently unlikely.
} 
are subject to bilateral negotiation.

\section{Conclusion}

In this paper I develop a theoretical model of a decentralized market with trading frictions. The trading process has three important features: pre-match communication, search frictions, and a strategic method of price determination. Traders on both sides of the market have the opportunity to post a public advertisement containing a bid or ask price. Traders that do not advertise a price instead observe all price announcements and search for a trading partner by targeting a particular price. Transaction prices are then determined in a bilateral bargaining game between a matched buyer and seller, where the posted price is interpreted as the initial offer in an alternating offer bargaining game. The advertisement therefore conveys commitment to a bid or ask price, but the counterparty that has not engaged in pre-match price publication maintains the ability to initiate ex post negotiation. In equilibrium, the posted price provides appropriate incentives for potential trading partners to direct their search, implementing the constrained efficient allocation. In a setting where the outcome of negotiations is not entirely predictable, posted prices tend to differ from transaction prices. The possibility of unfavorable outcomes in the bargaining procedure rationalizes the commonplace strategy of posting bid or ask prices even when posted prices tend to be different from transaction prices.

The environment is sufficiently tractable that it can be extended relatively easily along several dimensions. Generalizing the model to accommodate trader heterogeneity, for example, can account for the coexistence of bid and ask prices in equilibrium. A simulated example produces distributions of advertised prices and transaction prices that have qualitative properties in common with the price distributions observed in 
the decentralized secondary market for standard taxicab licenses (STLs) in Toronto. To my knowledge, these qualitative features of the price distributions cannot be explained by existing directed search models with limited commitment to posted prices. Moreover, the assets being traded are essentially identical, which rules out alternative interpretations of the role of advertised prices that rely on quality differences and inspection. The interpretation proposed here depends critically on two novel features of the model: (i) the possibility of ex post price negotiations, and (ii) strategic price posting decisions by traders on both sides of the market.

Many decentralized markets for financial securities, goods, and labor contracts are suitably approximated by the main features of the theoretical model: namely, search frictions, pre-match price announcements, and ex post bargaining. The insight that price posting emerges endogenously on the side of the market that has an advantage in bargaining is likely widely applicable. Presumably bargaining expertise improves with frequency of negotiations. In many markets, such as those for fixed income securities, vehicles, hotel rooms, and generic services provided by skilled tradespeople, advertised prices (e.g., published interest rate, manufacturer's suggested retail price, rack rate, or hourly rate) tend to come from the supply side: the side of the market negotiating on a regular basis. In labor markets, repeated employment contract negotiations on the demand side corresponds to the common occurrence of negotiable wage posting by employers. It seems plausible that publicly advertised pricing is adopted in these contexts to prevent skilled negotiators from exploiting weak ones in order to draw in potential counterparties/customers/clients/employees in the first place. 


\section{References}

Acemoglu, Daron and Robert Shimer. 1999. "Efficient Unemployment Insurance." Journal of Political Economy 107 (5):893-928.

Afonso, Gara and Ricardo Lagos. 2015. "Trade dynamics in the market for federal funds." Econometrica 83:263-313.

Albrecht, James, Pieter A. Gautier, and Susan Vroman. 2006. "Equilibrium directed search with multiple applications." Review of Economic Studies 73 (4):869-891.

—. 2014. "Efficient Entry in Competing Auctions." American Economics Review 104 (10):3288-3296.

—. 2015. "Directed search in the housing market." Review of Economic Dynamics $19(10): 218-231$.

Arnold, Michael A. 1999. "Search, bargaining and optimal asking prices." Real Estate Economics 27 (3):453-481.

Binmore, Ken. 1980. "Nash bargaining theory II." STICERD - theoretical economics paper series, Suntory and Toyota International Centres for Economics and Related Disciplines, LSE.

Binmore, Ken, Ariel Rubinstein, and Asher Wolinsky. 1986. "The Nash bargaining solution in economic modelling." RAND Journal of Economics 17 (2):176-188.

Burdett, Kenneth, Melvyn Coles, Nobuhiro Kiyotaki, and Randall Wright. 1995. "Buyers and Sellers: Should I Stay or Should I Go?" The American Economic Review 85 (2):281-286.

Burdett, Kenneth, Shouyong Shi, and Randall Wright. 2001. "Pricing and Matching with Frictions." Journal of Political Economy 109 (5):1060-1085.

Camera, Gabriele and Cemil Selcuk. 2009. "Price dispersion with directed search." Journal of the European Economic Association 7 (6):1193-1224.

Chen, Yongmin and Robert W. Rosenthal. 1996a. "Asking prices as commitment 
devices." International Economic Review 37 (1):129-155.

—. 1996b. "On the use of ceiling-price commitments by monopolists." The RAND Journal of Economics 27 (2):207-220.

City of Toronto. 2012. "Toronto's Taxicab Industry." Discussion Paper.

Delacroix, Alain and Shouyong Shi. 2018. "Should Buyers or sellers organize trade in a frictional market?" The Quarterly Journal of Economics 133 (4):2171-2214.

Diamond, Peter A. 1982. "Wage determination and efficiency in search equilibrium." The Review of Economic Studies 49 (2):217-227.

Doyle, Matthew and Jacob Wong. 2013. "Wage posting without full commitment." Review of Economic Dynamics 16 (2):231-252.

Duffie, Darrell, Nicolae Gârleanu, and Lasse Heje Pedersen. 2007. "Valuation in over-the-counter markets." Review of Financial Studies 20 (6):1865-1900.

Halko, Marja-Liisa, Klaus Kultti, and Juha Virrankoski. 2008. "Search direction and wage dispersion." International Economic Review 49 (1):111-134.

Hosios, Arthur J. 1990. "On the efficiency of matching and related models of search and unemployment." Review of Economic Studies 57 (2):279-298.

Hugonnier, Julien, Benjamin Lester, and Pierre-Olivier Weill. 2014. "Heterogeneity in decentralized asset markets." Working Paper w20746, National Bureau of Economic Research.

Julien, Benoit, John Kennes, and Ian King. 2000. "Bidding for labor." Review of Economic Dynamics 3 (4):619-649.

Kim, Kyungmin and Philipp Kircher. 2015. "Efficient competition through cheap talk: the case of competing auctions." Econometrica 83 (5):1849-1875.

Kultti, Klaus, Antti Miettunen, Tuomas Takalo, and Juha Virrankoski. 2009. "Who searches?" The Japanese Economic Review 60 (2):152-171.

Lester, Benjamin, Guillaume Rocheteau, and Pierre-Olivier Weill. 2015. "Competing for order flow in OTC markets." Journal of Money, Credit and Banking 47 (S2):77- 
126.

Lester, Benjamin, Ludo Visschers, and Ronald Wolthoff. 2017. "Competing with asking prices." Theoretical Economics 12 (2):731-770.

Menzio, Guido. 2007. "A theory of partially directed search." Journal of Political Economy 115 (5):748-769.

Moen, Espen R. 1997. "Competitive search equilibrium." Journal of Political Economy 105 (2):385-411.

Montgomery, James D. 1991. "Equilibrium wage dispersion and interindustry wage differentials." The Quarterly Journal of Economics 106 (1):163-79.

Mortensen, Dale T. 1982a. "The matching process as a noncooperative bargaining game." In The Economics of Information and Uncertainty, NBER Chapters, chap. 7. National Bureau of Economic Research, Inc, 233-258.

—. 1982b. "Property rights and efficiency in mating, racing, and related games." American Economic Review 72 (5):968-79.

Mortensen, Dale T and Christopher A Pissarides. 1994. "Job creation and job destruction in the theory of unemployment." Review of Economic Studies 61 (3):397-415.

Myerson, Roger B. 1991. Game theory: analysis of conflict. Harvard University Press.

Peters, Michael. 1991. "Ex ante price offers in matching games non-steady states." Econometrica 59 (5):1425-1454.

Peters, Michael and Sergei Severinov. 1997. "Competition among sellers who offer auctions instead of prices." Journal of Economic Theory 75 (1):141-179.

Pissarides, Christopher A. 1984. "Search intensity, job advertising, and efficiency." Journal of Labor Economics 2 (1):128-43.

—. 1985. "Short-run equilibrium dynamics of unemployment vacancies, and real wages." American Economic Review 75 (4):676-90.

Rocheteau, Guillaume and Pierre-Olivier Weill. 2011. "Liquidity in frictional asset markets." Journal of Money, Credit and Banking 43:261-282. 
Schelling, Thomas C. 1956. "An essay on bargaining." The American Economic Review 46 (3):281-306.

Stacey, Derek. 2016. "Commitment and costly signal ing in decentralized markets." International Economic Review 57 (4):1507-1533.

Watanabe, Makoto. 2013. "Middlemen: A directed search equilibrium approach." Working paper, VU University Amsterdam, Tinbergen Institute.

\section{A Omitted Proofs}

\section{Proof of Lemma 4}

Adopting a similar structure to that found in Acemoglu and Shimer (1999), the proof of Lemma 4 proceeds in three steps. In step 1 it is established that if $\left\langle\mathbb{P}_{t}^{a}, \mathbb{P}_{t}^{b}, \theta_{t}, V_{t}^{n}, V_{t}^{m}, V_{t}^{s}\right\rangle$ is a directed search equilibrium at time $t$, then any $p \in \mathbb{P}_{t}^{i}$ for $i \in\{a, b\}$ is such that $P_{t}^{*}=P_{t}(i, p)$ and $\theta_{t}^{*}=\theta_{t}(i, p)$ solve

$$
\max _{P, \theta} \gamma(\theta)\left(P-V_{t+1}^{s}\right)
$$

subject to

$$
\beta\left[\lambda(\theta)\left(V_{t+1}^{m}-P\right)+(1-\lambda(\theta)) V_{t+1}^{n}\right]=c_{l} .
$$

Step 2 is a proof of the converse: if some $\left(P_{t}^{*}, \theta_{t}^{*}\right)$ solves this problem and $P_{t}(i, p)=P_{t}^{*}$, then there exists an equilibrium with $p \in \mathbb{P}_{t}^{i}$ and $\theta_{t}(i, p)=\theta_{t}^{*}$. Existence of a unique solution to this problem, denoted $\left(P_{t}^{*}, \theta_{t}^{*}\right)$ and characterized by (11) and (12), is ascertained in step 3. Finally, that there exist $i \in\{a, b\}$ and $p \in \mathbb{R}_{+}$such that $P_{t}(i, p)=P_{t}^{*}$ follows from Lemma 3 .

Step 1. Let $\left\langle\mathbb{P}_{t}^{a}, \mathbb{P}_{t}^{b}, \theta_{t}, V_{t}^{n}, V_{t}^{m}, V_{t}^{s}\right\rangle$ be a directed search equilibrium at time $t$ with $p \in \mathbb{P}_{t}^{i}$ for $i \in\{a, b\}$. Let $P_{t}^{*}=P_{t}(i, p)$ and $\theta_{t}^{*}=\theta_{t}(i, p)$. Part (i) of Definition 1 
and $p \in \mathbb{P}_{t}^{i}$ guarantee that $\left(P_{t}^{*}, \theta_{t}^{*}\right)$ satisfies constraint (A.2). Part (iii) of Definition 1 and $p \in \mathbb{P}_{t}^{i}$ imply

$$
d-c_{h}+\beta\left[\gamma\left(\theta_{t}^{*}\right) P_{t}^{*}+\left(1-\gamma\left(\theta_{t}^{*}\right)\right) V_{t+1}^{s}\right]=V_{t}^{s} .
$$

Now consider ask price $V_{t+1}^{s}$ so that $P_{t}\left(a, V_{t+1}^{s}\right)=V_{t+1}^{s}$. Part (iii) of Definition 1 then implies

$$
d-c_{h}+\beta V_{t+1}^{s} \leq V_{t}^{s} .
$$

Suppose another pair $\left(P^{\prime}, \theta^{\prime}\right)$ achieves a higher value of the objective so that

$$
d-c_{h}+\beta\left[\gamma\left(\theta^{\prime}\right) P^{\prime}+\left(1-\gamma\left(\theta^{\prime}\right)\right) V_{t+1}^{s}\right]>V_{t}^{s} .
$$

Combining (A.3) and (A.4) establishes that $P^{\prime}>V_{t+1}^{s}$. To prove that $\left(P^{\prime}, \theta^{\prime}\right)$ cannot satisfy constraint (A.2), suppose (FSOC) that it does:

$$
\beta\left[\lambda\left(\theta^{\prime}\right)\left(V_{t+1}^{m}-P^{\prime}\right)+\left(1-\lambda\left(\theta^{\prime}\right)\right) V_{t+1}^{n}\right]=c_{l}
$$

Given that $\beta V_{t+1}^{n}<c_{l}$, this requires $P^{\prime}<V_{t+1}^{m}-V_{t+1}^{n}$.

By part (iv) of Lemma 3 there exist $p^{\prime} \in \mathbb{R}_{+}$and $i^{\prime} \in\{a, b\}$ such that $P_{t}\left(i^{\prime}, p^{\prime}\right)=$ $P^{\prime}$. Since $\left\langle\mathbb{P}_{t}^{a}, \mathbb{P}_{t}^{b}, \theta_{t}, V_{t}^{n}, V_{t}^{m}, V_{t}^{s}\right\rangle$ is a directed search equilibrium, part (iii) of Definition 1 requires

$$
d-c_{h}+\beta\left[\gamma\left(\theta_{t}\left(i^{\prime}, p^{\prime}\right)\right) P_{t}\left(i^{\prime}, p^{\prime}\right)+\left(1-\gamma\left(\theta_{t}\left(i^{\prime}, p^{\prime}\right)\right)\right) V_{t+1}^{s}\right] \leq V_{t}^{s} .
$$

Inequalities (A.4), (A.5) and $P^{\prime}>V_{t+1}^{s}$ imply $\gamma\left(\theta^{\prime}\right)>\gamma\left(\theta_{t}\left(i^{\prime}, p^{\prime}\right)\right)$ and hence $\lambda\left(\theta^{\prime}\right)<\lambda\left(\theta_{t}\left(i^{\prime}, p^{\prime}\right)\right)$. 
Therefore,

$$
\beta \lambda\left(\theta^{\prime}\right)\left(V_{t+1}^{m}-V_{t+1}^{n}-P^{\prime}\right)<\beta \lambda\left(\theta_{t}\left(i^{\prime}, p^{\prime}\right)\right)\left(V_{t+1}^{m}-V_{t+1}^{n}-P_{t}\left(i^{\prime}, p^{\prime}\right)\right) \leq c_{l}-\beta V_{t+1}^{n},
$$

where the first inequality uses $\lambda\left(\theta^{\prime}\right)<\lambda\left(\theta_{t}\left(i^{\prime}, p^{\prime}\right)\right)$ and $P_{t}\left(i^{\prime}, p^{\prime}\right)=P^{\prime}<V_{t+1}^{m}-V_{t+1}^{n}$, and the last inequality applies part (i) of Definition 1. This contradiction establishes that the pair $\left(P^{\prime}, \theta^{\prime}\right)$ must violate constraint (A.2).

Step 2. Let $\left(P_{t}^{*}, \theta_{t}^{*}\right)$ denote a solution to the constrained optimization problem and consider a pair $\left(i^{*}, p^{*}\right)$ satisfying $P_{t}\left(i^{*}, p^{*}\right)=P_{t}^{*}$. Construct an equilibrium as follows: $\mathbb{P}_{t}^{i^{*}}=\left\{p^{*}\right\} ; \mathbb{P}_{t}^{-i^{*}}=\emptyset$;

$$
\begin{aligned}
& V_{t}^{n}=0 \\
& V_{t}^{m}=d-c_{l}+\beta\left[(1-\delta) V_{t+1}^{m}+\delta V_{t+1}^{s}\right] \\
& V_{t}^{s}=d-c_{h}+\beta\left[\gamma\left(\theta_{t}^{*}\right) P_{t}^{*}+\left(1-\gamma\left(\theta_{t}^{*}\right)\right) V_{t+1}^{s}\right]
\end{aligned}
$$

and let $\theta_{t}$ satisfy

$$
\beta\left[\lambda\left(\theta_{t}(a, p)\right)\left(V_{t+1}^{m}-P_{t}(a, p)\right)+\left(1-\lambda\left(\theta_{t}(a, p)\right)\right) V_{t+1}^{n}\right]=c_{l},
$$

or $\theta_{t}(a, p)=0$ if there is no solution to this equation, and

$$
d-c_{h}+\beta\left[\gamma\left(\theta_{t}(b, p)\right) P_{t}(b, p)+\left(1-\gamma\left(\theta_{t}(b, p)\right)\right) V_{t+1}^{s}\right]=V_{t}^{s},
$$

or $\theta_{t}(b, p)=\infty$ if there is no solution to this equation.

Notice that since the pair $(P, \theta)=\left(V_{t+1}^{m}+\left((1-\lambda(0)) \beta V_{t+1}^{n}-c_{l}\right) /(\beta \lambda(0)), 0\right)$ satisfies constraint (A.2), it must be that

$$
\gamma\left(\theta_{t}^{*}\right)\left(P_{t}^{*}-V_{t+1}^{s}\right) \geq 0
$$


which implies $P_{t}^{*} \geq V_{t+1}^{s}$ and $V_{t}^{s} \geq d-c_{h}+\beta V_{t+1}^{s}$.

It is clear that $\left\langle\mathbb{P}_{t}^{a}, \mathbb{P}_{t}^{b}, \theta_{t}, V_{t}^{n}, V_{t}^{m}, V_{t}^{s}\right\rangle$ satisfies part (ii) of Definition 1, part (i) with $i=a$ and part (iii) with $i=b$.

Suppose (FSOC) that some pair $\left(b, p^{\prime}\right)$ violates part (i) of Definition 1:

$$
\beta\left[\lambda\left(\theta_{t}\left(b, p^{\prime}\right)\right)\left(V_{t+1}^{m}-P_{t}\left(b, p^{\prime}\right)\right)+\left(1-\lambda\left(\theta_{t}\left(b, p^{\prime}\right)\right)\right) V_{t+1}^{n}\right]>c_{l} .
$$

Given that $\beta V_{t+1}^{n}<c_{l}$, it follows that $\theta_{t}\left(b, p^{\prime}\right)<\infty$. Choose $\theta^{\prime}>\theta_{t}\left(b, p^{\prime}\right)$ satisfying

$$
\beta\left[\lambda\left(\theta^{\prime}\right)\left(V_{t+1}^{m}-P_{t}\left(b, p^{\prime}\right)\right)+\left(1-\lambda\left(\theta^{\prime}\right)\right) V_{t+1}^{n}\right]=c_{l} .
$$

By the construction of $\theta_{t}$ and $P_{t}, \theta^{\prime}>\theta_{t}\left(b, p^{\prime}\right)$ implies

$$
\left.d-c_{h}+\beta\left[\gamma\left(\theta^{\prime}\right) P_{t}\left(b, p^{\prime}\right)+\left(1-\gamma\left(\theta^{\prime}\right)\right)\right) V_{t+1}^{s}\right]>V_{t}^{s} .
$$

The pair $\left(P_{t}\left(b, p^{\prime}\right), \theta^{\prime}\right)$ satisfies constraint (A.2) and achieves a higher value of the objective than $\left(P_{t}^{*}, \theta_{t}^{*}\right)$ : a contradiction.

Suppose (FSOC) that some pair $\left(a, p^{\prime \prime}\right)$ violates part (iii) of Definition 1:

$$
d-c_{h}+\beta\left[\gamma\left(\theta_{t}\left(a, p^{\prime \prime}\right)\right) P_{t}\left(a, p^{\prime \prime}\right)+\left(1-\gamma\left(\theta_{t}\left(a, p^{\prime \prime}\right)\right)\right) V_{t+1}^{s}\right]>V_{t}^{s} .
$$

Since it was previously established that $V_{t}^{s} \geq d-c_{h}+\beta V_{t+1}^{s}$, this strict inequality requires $\theta_{t}\left(a, p^{\prime \prime}\right)>0$. Then, by the construction of $\theta_{t}$,

$$
\beta\left[\lambda\left(\theta_{t}\left(a, p^{\prime \prime}\right)\right)\left(V_{t+1}^{m}-P_{t}\left(a, p^{\prime \prime}\right)\right)+\left(1-\lambda\left(\theta_{t}\left(a, p^{\prime \prime}\right)\right)\right) V_{t+1}^{n}\right]=c_{l} .
$$

The pair $\left(P_{t}\left(a, p^{\prime \prime}\right), \theta_{t}\left(a, p^{\prime \prime}\right)\right)$ satisfies constraint (A.2) and achieves a higher value of the objective than $\left(P_{t}^{*}, \theta_{t}^{*}\right)$ : a contradiction. 
Step 3. Substituting constraint (A.2) into objective (A.1) yields the following optimization problem:

$$
\max _{\theta} \beta \gamma(\theta)\left(V_{t+1}^{m}-V_{t+1}^{n}-V_{t+1}^{s}\right)-\theta\left(c_{l}-\beta V_{t+1}^{n}\right)
$$

The objective in (A.6) is continuous and concave in $\theta$. Since $c_{l}<\beta \lambda(0)\left[V_{t+1}^{m}-V_{t+1}^{n}-V_{t+1}^{s}\right]$, there is a unique $\bar{\theta} \in(0, \infty)$ that solves $\beta\left[\lambda(\bar{\theta})\left(V_{t+1}^{m}-V_{t+1}^{s}\right)+(1-\lambda(\bar{\theta})) V_{t+1}^{n}\right]=c_{l}$. The objective in (A.6) is zero at both $\theta=0$ and $\theta=\bar{\theta}$. These properties ensure that the solution to problem (A.6), denoted $\theta_{t}^{*}$, is unique and lies in $(0, \bar{\theta})$. The following first order condition is both necessary and sufficient to identify $\theta_{t}^{*}$ :

$$
\beta\left[\gamma^{\prime}\left(\theta_{t}^{*}\right)\left(V_{t+1}^{m}-V_{t+1}^{s}\right)+\left(1-\gamma^{\prime}\left(\theta_{t}^{*}\right)\right) V_{t+1}^{n}\right]=c_{l}
$$

Let $P_{t}^{*}$ satisfy constraint (A.2) with $\theta=\theta_{t}^{*}$ :

$$
\beta\left[\lambda\left(\theta_{t}^{*}\right)\left(V_{t+1}^{m}-P_{t}^{*}\right)+\left(1-\lambda\left(\theta_{t}^{*}\right)\right) V_{t+1}^{n}\right]=c_{l} .
$$

Combining (A.7), (A.8) and $\gamma\left(\theta_{t}^{*}\right)=\theta_{t}^{*} \lambda\left(\theta_{t}^{*}\right)$, and rearranging for $P_{t}^{*}$ yields

$$
P_{t}^{*}=V_{t+1}^{s}+\left(1-\frac{\theta_{t}^{*} \gamma^{\prime}\left(\theta_{t}^{*}\right)}{\gamma\left(\theta_{t}^{*}\right)}\right)\left(V_{t+1}^{m}-V_{t+1}^{n}-V_{t+1}^{s}\right)
$$

The pair $\left(P_{t}^{*}, \theta_{t}^{*}\right)$ represents the unique solution to the constrained optimization problem. By part (iv) of Lemma 3, there exist $i^{*}$ and $p^{*}$ such that $P_{t}\left(i^{*}, p^{*}\right)=P_{t}^{*}$. By step 2, the pairs $\left(i^{*}, p^{*}\right)$ and $\left(P_{t}^{*}, \theta_{t}^{*}\right)$ can be used to construct an equilibrium. Moreover, the result established in step 1 ensures that any $p \in \mathbb{P}_{t}^{i}$ for $i \in\{a, b\}$ is such that $P_{t}(i, p)=P_{t}^{*}$ and $\theta_{t}(i, p)=\theta_{t}^{*}$.

Proof of Proposition 1 
It was established in step 3 of the proof of Lemma 4 that $\theta_{t}^{*}$ is unique, positive and finite. Since $\eta$ is the elasticity of the matching function with respect to $s$, the properties of $\mathcal{M}$ imply $0<\eta\left(\theta_{t}^{*}\right)<1$. First consider the case in which $0<\eta\left(\theta_{t}^{*}\right)<\int_{0}^{1} \phi d F$. Given (3) and (12), these inequalities are equivalent to $V_{t+1}^{s}<P_{t}^{*}<\mathbb{E}\left[\hat{p}_{t}\right]$. Parts (i) and (ii) of Lemma 3 imply a unique $(a, p)$ satisfying $P_{t}(a, p)=P_{t}^{*}$, while part (iii) of Lemma 3 precludes a solution to $P_{t}(b, p)=P_{t}^{*}$. $\mathbb{P}_{t}^{a}$ is therefore a singleton and $\mathbb{P}_{t}^{b}=\emptyset$.

Next consider $\int_{0}^{1} \phi d F<\eta\left(\theta_{t}^{*}\right)<1$ which, given (3) and (12), is equivalent to $\mathbb{E}\left[\hat{p}_{t}\right]<P_{t}^{*}<V_{t+1}^{m}-V_{t+1}^{n}$. Parts (i) and (iii) of Lemma 3 imply a unique $(b, p)$ satisfying $P_{t}(b, p)=P_{t}^{*}$, while part (ii) of Lemma 3 precludes $P_{t}(a, p)=P_{t}^{*}$. In this case, $\mathbb{P}_{t}^{b}$ is a singleton and $\mathbb{P}_{t}^{a}=\emptyset$.

\section{Proof of Proposition 2}

Consider a first-order stochastic dominant shift from $F$ to $G$ so that $G(\phi) \leq F(\phi)$ for all $\phi \in[0,1]$. This relationship and part (iv) of Definition 2 imply

$$
\int_{0}^{\frac{p-V^{s}}{V^{m}-V^{s}}}[1-G(\phi)] d \phi \geq \int_{0}^{\frac{p-V^{s}}{V^{m}-V^{s}}}[1-F(\phi)] d \phi=\eta(\theta)
$$

for any $p \in \mathbb{P}^{a}$, and

$$
\int_{\frac{p-V^{s}}{V^{m}-V^{s}}}^{1} G(\phi) d \phi \leq \int_{\frac{p-V^{s}}{V^{m}-V^{s}}}^{1} F(\phi) d \phi=1-\eta(\theta)
$$

for any $p \in \mathbb{P}^{b}$. These inequalities imply a reduction in the posted bid or ask price in the case of first-order stochastic dominance.

Now consider a mean preserving spread from $F$ to $G$. A mean preserving spread is a special case of second-order stochastic dominance: $\int_{0}^{\Phi} G(\phi) d \phi \geq \int_{0}^{\Phi} F(\phi) d \phi$ for 
all $\Phi \in[0,1]$. This relationship and part (iv) of Definition 2 imply

$$
\int_{0}^{\frac{p-V^{s}}{V^{m}-V^{s}}}[1-G(\phi)] d \phi \leq \int_{0}^{\frac{p-V^{s}}{V^{m}-V^{s}}}[1-F(\phi)] d \phi=\eta(\theta)
$$

for any $p \in \mathbb{P}^{a}$. It follows that any equilibrium ask price must increase in the case of a mean preserving spread.

Notice that we can use the complementary CDF to write the expected value of the stochastic bargaining power as

$$
\mathbb{E}_{F}[\phi]=\int_{0}^{1}[1-F(\phi)] d \phi=1-\int_{0}^{\Phi} F(\phi) d \phi-\int_{\Phi}^{1} F(\phi) d \phi
$$

for any $\Phi \in[0,1]$. The second-order stochastic dominance relationship thus implies

$$
1-\mathbb{E}_{G}[\phi]-\int_{\Phi}^{1} G(\phi) d \phi=\int_{0}^{\Phi} G(\phi) d \phi \geq \int_{0}^{\Phi} F(\phi) d \phi=1-\mathbb{E}_{F}[\phi]-\int_{\Phi}^{1} F(\phi) d \phi
$$

for any $\Phi \in[0,1]$. The special case of equal means yields

$$
\int_{\Phi}^{1} G(\phi) d \phi \leq \int_{\Phi}^{1} F(\phi) d \phi, \quad \Phi \in[0,1]
$$

Finally, setting $\Phi=\left(p-V^{s}\right) /\left(V^{m}-V^{s}\right)$ and applying part (iv) of Definition 2 gives

$$
\int_{\frac{p-V^{s}}{V^{m}-V^{s}}}^{1} G(\phi) d \phi \leq \int_{\frac{p-V^{s}}{V^{m}-V^{s}}}^{1} F(\phi) d \phi=1-\eta(\theta)
$$

for any $p \in \mathbb{P}^{b}$. Once again this inequality implies that any equilibrium bid price must decline in the case of a mean preserving spread.

\section{Proof of Proposition 3}

An equivalent formulation of the constrained social planner's problem designates 
a sequence for market tightness, $\left\{\theta_{t}\right\}_{t=0}^{\infty}$, given the matching technology and the evolution of the distribution of traders:

$$
\max _{\left\{\theta_{t}\right\}_{t=0}^{\infty}} \sum_{t=0}^{\infty} \beta^{t}\left[\left(A-s_{t}\right)\left(d-c_{l}\right)+s_{t}\left(d-c_{h}\right)-\theta_{t} s_{t} c_{l}\right]
$$

subject to the law of motion for the number of sellers, $s_{t+1}=s_{t}-\gamma\left(\theta_{t}\right) s_{t}+\delta\left(A-s_{t}\right)$ for all $t$. The recursive formulation of the planner's problem is

$$
W\left(s_{t}\right)=\max _{\theta_{t}}\left\{\left(A-s_{t}\right)\left(d-c_{l}\right)+s_{t}\left(d-c_{h}\right)-\theta_{t} s_{t} c_{l}+\beta W\left(s_{t+1}\right)\right\}
$$

subject to $s_{t+1}=s_{t}-\gamma\left(\theta_{t}\right) s_{t}+\delta\left(A-s_{t}\right)$. The steady state version of the Euler equation, derived from the first-order and Benveniste-Scheinkman conditions, is

$$
c_{l}=\beta \lambda(\theta)(1-\eta(\theta))\left(\frac{c_{h}-c_{l}}{1-\beta(1-\delta-\gamma(\theta) \eta(\theta))}\right)
$$

This above condition determines the constrained efficient ratio of buyers to sellers, evaluated in a steady state.

For comparison purposes, the free-entry condition in a steady state equilibrium is $c_{l}=\beta \lambda(\theta)(1-\eta(\theta))\left[V^{m}-V^{s}\right]$ (see equation (20) in part (ii) of Definition 2). Moreover, subtracting (19) from (18) yields an expression for the steady state equilibrium match surplus:

$$
V^{m}-V^{s}=\frac{c_{h}-c_{l}}{1-\beta(1-\delta-\gamma(\theta) \eta(\theta))}
$$

Substituting (A.11) into the steady state equilibrium free entry condition yields (A.10): the condition for constrained efficiency. Decentralized market entry in a steady state equilibrium is therefore constrained efficient. 